\title{
FOOD SYSTEMS FOR CHILDREN AND ADOLESCENTS
}

\section{WORKING TOGETHER TO SECURE NUTRITIOUS DIETS}

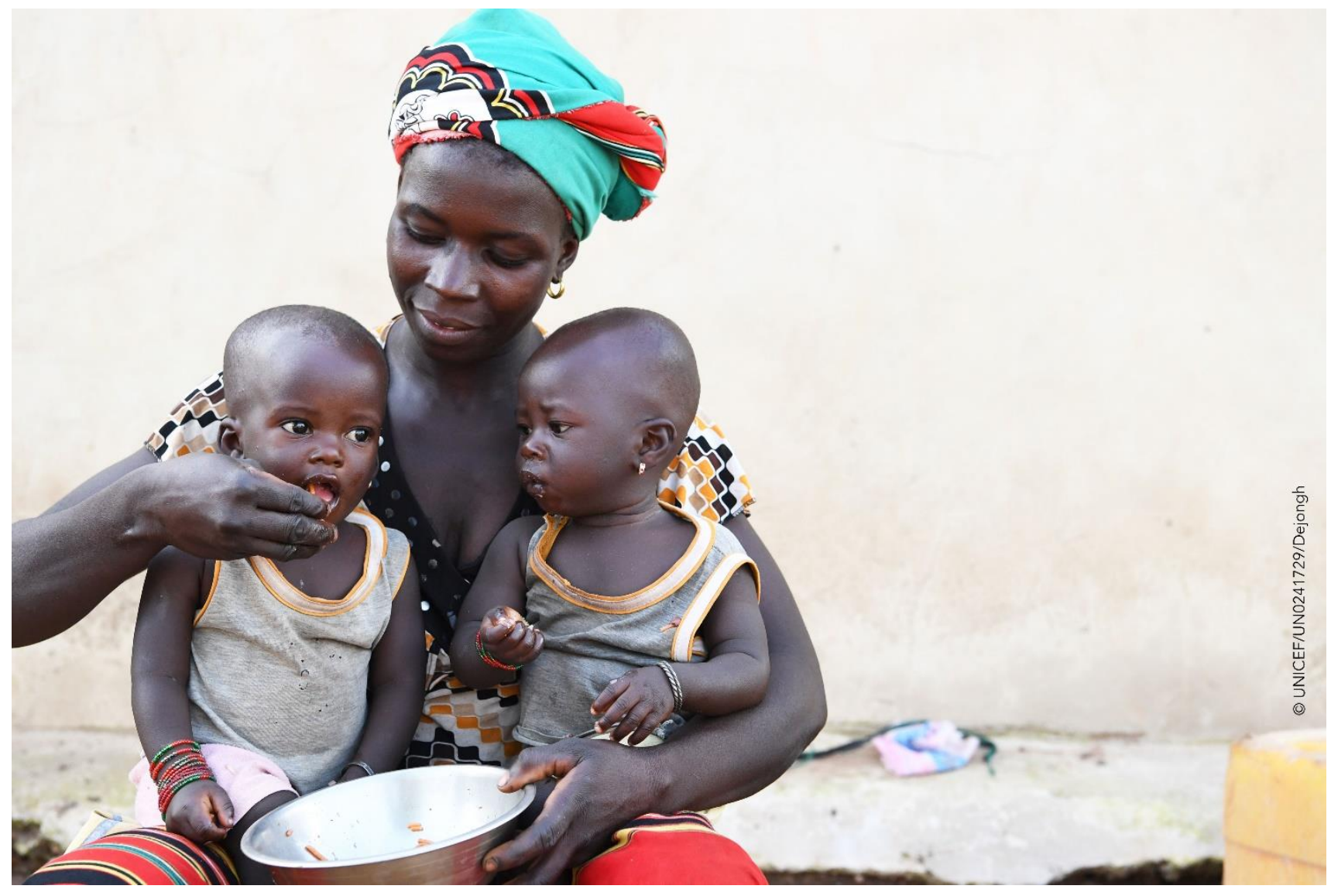

GAIN Convening Paper Series n³

July, 2019 


\section{ABOUT GAIN}

The Global Alliance for Improved Nutrition (GAIN) is a Swiss-based foundation launched the UN in 2002 to tackle the human suffering caused by malnutrition. Working with governments, businesses and civil society, we aim to transform food systems so that they deliver more nutritious food for all people, especially the most vulnerable.

\section{Recommended citation}

UNICEF, GAIN. Food Systems for Children and Adolescents: working together to secure nutritious diets. New York: UNICEF; 2019. DOI: https://doi.org/10.36072/cp.3

\section{(C) The Global Alliance for Improved Nutrition (GAIN)}

The contribution of third parties do not necessarily represent the view or opinion of GAIN.

\section{Acknowledgements}

The meeting was convened by UNICEF and GAIN, and the core meeting organizing team was comprised of Nita Dalmiya (UNICEF), Jessica Fanzo (FAO), Elizabeth Fox (Johns Hopkins University), Joyce Greene (GAIN), Roland Kupka (UNICEF), Saul Morris (GAIN), Ahmed Raza (FAO), and Arnold Timmer (GAIN).

The organizers would like to thank the Ministry of Foreign Affairs of the Kingdom of the Netherlands for support of this consultation; colleagues at UNICEF Office of Research - Innocenti for hosting the consultation in Florence; Nona Reuter (UNICEF), Tatiana Harmon (UNICEF), and Cristina Hayde Perez Gonzalez (UNICEF) for their logistical and technical assistance; Jane Badham for facilitating the consultation; the external expert reviewers of the child characteristics table and framework for their feedback prior to the consultation (Alida Melse, Carmen Burbano, Carolyn Steel, Daniela Neri, Gretel Pelto); the consultants who prepared materials in advance of the consultation (Kendra Siekmans, Ty Beal, Alison Tumilowicz, Saul Morris, Alessandro Demaio, Jenna Hollis, Clare Collins, Fabrice DeClerck, Karen McColl); the families of Huruma and Tirion, Gabriela and Erik, and Rafsi and Marsa who allowed us to video record them; and the participants in the consultation for their participation and contributions (Annex 2).

All photographs included in this document have been taken with consent for use in publications.

\section{GAIN CONVENING PAPER SERIES}

The GAIN Convening Paper Series brings together proceedings and reports from events that have been convened or co-convened by GAIN.

The Global Alliance for Improved Nutrition (GAIN)

Rue de Varembé 7

1002 Geneva

Switzerland

$\mathrm{T}:$ +41 227491850

E: info@gainhealth.org

www.gainhealth.org 


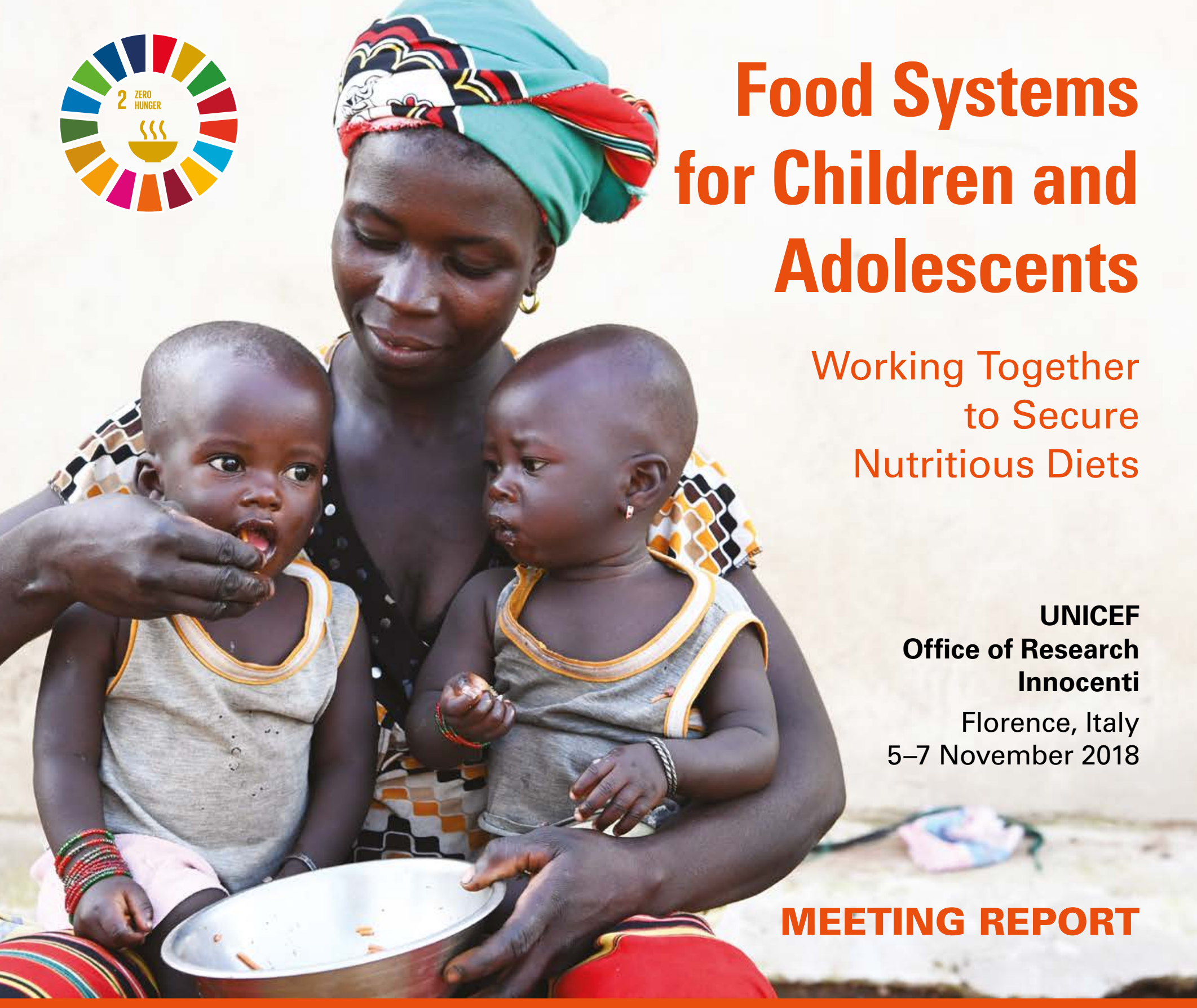

A GLOBAL CONSULTATION CO-HOSTED BY:

\section{unicef}

With the support of the

Ministry of Foreign Affairs of the

Kingdom of the Netherlands gain 


\section{Acknowledgements}

The meeting was convened by UNICEF and GAIN and the core meeting organizing team was comprised of Nita Dalmiya (UNICEF), Jessica Fanzo (FAO), Elizabeth Fox (Johns Hopkins University), Joyce Greene (GAIN), Roland Kupka (UNICEF), Saul Morris (GAIN), Ahmed Raza (FAO), and Arnold Timmer (GAIN).

The organizers would like to thank the Ministry of Foreign Affairs of the Kingdom of the Netherlands for the support to this consultation; the colleagues at UNICEF Office of Research - Innocenti for hosting the consultation in Florence; Nona Reuter (UNICEF) for graphic design; Tatiana Harmon (UNICEF) and Cristina Hayde Perez Gonzalez (UNICEF) for their logistical and technical assistance; Jane Badham for facilitating the consultation; the external expert reviewers of the child characteristics table and framework for their feedback prior to the consultation (Alida Melse, Carmen Burbano, Carolyn Steel, Daniela Neri, Gretel Pelto); the consultants that prepared materials in advance of the consultation (Kendra Siekmans, Ty Beal, Alison Tumilowicz, Saul Morris, Alessandro Demaio, Jenna Hollis, Clare Collins, Fabrice DeClerck, Karen McColl); the families of Huruma and Tirion, Gabriela and Erik, and Rafsi and Marsa who allowed for us to video record them; and the participants of the Innocenti consultation for their participation and contributions during the consultation (Annex 2).

Photo credit for cover: @UNICEF/UN0241729/Dejongh 


\section{Contents}

$\begin{array}{lr}\text { Acknowledgements } & 2\end{array}$

$\begin{array}{ll}\text { List of Figures } & 5\end{array}$

$\begin{array}{ll}\text { List of Boxes } & 5\end{array}$

$\begin{array}{lr}\text { Key Messages } & 6\end{array}$

Why is a food systems approach needed to address poor diets of children and adolescents?

What are the age-specific characteristics and nutritional needs of children and adolescents?

The current state of children and adolescents' diets

Why are children and adolescents not receiving the diets they need for optimal development?

Interpersonal and socio-cultural factors

Economic, physical and environmental factors

Summary

What is a food systems approach for children and adolescents?

The Innocenti Framework on Food Systems for Children and Adolescents 19

$\begin{array}{ll}\text { Elements of the framework } & 20\end{array}$

$\begin{array}{ll}\text { Drivers of food systems } & 21\end{array}$

$\begin{array}{ll}\text { Determinants and influencers of food systems } & 22\end{array}$

$\begin{array}{ll}\text { Food supply chains } & 22\end{array}$

$\begin{array}{ll}\text { External food environments } & 25\end{array}$

$\begin{array}{ll}\text { Personal food environments } & 28\end{array}$ 
Behaviours of caregivers, children and adolescents 30

The interactions in the food system $\quad 32$

$\begin{array}{ll}\text { Diets of children and adolescents } & 33\end{array}$

How can a food systems approach improve children and adolescents" diets? 34

$\begin{array}{ll}\text { A food systems approach to improve children and adolescents' diets } & 34\end{array}$

$\begin{array}{ll}\text { Gaps, needs, and opportunities } & 34\end{array}$

$\begin{array}{lr}\text { Conclusions and next steps } & 40\end{array}$

List of Participants $\quad 42$

$\begin{array}{lr}\text { References } & 45\end{array}$ 


\section{List of Figures}

Figure 1. The Innocenti Framework on food systems for children and adolescents

Figure 2. Drivers of food systems

Figure 3. Food supply chains and their influencers

Figure 4. External food environments and their influencers

Figure 5. Personal food environments and their influencers

Figure 6. Behaviours of caregivers, children and adolescents and their influencers

Figure 7. Arrows that connect the different determinants of the framework to one another

\section{List of Boxes}

Box 1. What are the age-specific characteristics and nutritional needs of children?

Box 2. What do we know (and not know) about healthy diets for children?

Box 3. Why develop a systems framework?

Box 4. Definitions related to the Innocenti Framework

Box 5. Field insights to support egg production as a source of nutrition for young children in East Africa, South Asia, and Southeast Asia

Box 6. Successes and challenges of improving the external food environment for children in Mexico

Box 8. Emotional demonstrations ("Emo-Demos") in East Java, Indonesia to improve infant feeding behaviours

Box 9. Steps to identify context-tailored food systems solutions to secure nutritious, safe, affordable, and sustainable diets for children and adolescents

Box 10. Summary of case study videos

Box 11. Supporting the development of a nutrition-friendly private sector in Africa 


\section{KEY MESSAGES}

- Improving children and adolescents' diets remains a major challenge in the 21st century. In many parts of the world, children and adolescents do not receive the diets they need - in quantity, frequency, and quality - to survive, grow, and develop to their full potential.

- Children and adolescents' physiological and psychosocial characteristics and their experiences with their interpersonal and socio-ecological environments change as they get older. With increasing independence, children and adolescents become principal actors in securing their diets.

- Broader food system issues need to be addressed to improve the diets of children and adolescents. Food systems are essential to delivering nutritious, safe, affordable, and sustainable diets, but the nutritional needs of children and adolescents (both of present and future generations) are often not prioritized.

- To better align food systems and the diets of children and adolescents, the Innocenti Framework on food systems for children and adolescents was developed. The framework comprises a set of drivers, plus four determinants (food supply chains, external food environments, personal food environments, and behaviours of caregivers, children and adolescents), which together influence the diets of children and adolescents.

- A food systems approach helps decisionmakers align food systems actions with the goals of secure diets for children and adolescents in the long-term, in a way that minimizes negative trade-offs and externalities across the food system. 
- Actions that have the potential to improve children and adolescents' diets need to be context-specific. However, general priorities emerged from the consultation to:

\section{Identify incentives and disincentives} that encourage actors across food supply chains and food environments to protect, promote, and support healthy diets for children and adolescents, including support for innovation, nutrition-focused financing policies, local procurement, and infrastructure investment;

2. Develop clear and easy-tounderstand guidelines on healthy diets for children and adolescents;

\section{Develop and enforce standards for} school feeding programmes and social protection schemes that align with guidelines;

4. Define principles of engagement with private sector actors that seek the best interests of children and adolescents, promote accountability, and avoid conflict of interest; and

5. Fill information gaps related to what children and adolescents eat, how they make their food decisions, and how to stimulate demand for healthy foods among children and adolescents and their caregivers.

- By integrating a food systems approach for children and adolescents into global strategies, we can make food systems work better to secure nutritious, safe, affordable, and sustainable diets that support optimal growth and development in children and adolescents. 


\section{WHY IS A FOOD SYSTEMS APPROACH NEEDED TO ADDRESS POOR DIETS OF CHILDREN AND ADOLESCENTS?}

Malnutrition, in all of its forms, is a problem of global proportion and requires urgent action. Nearly 151 million children under-five are stunted around the world, and though the prevalence of stunting is declining, it is not declining in all regions or at a sufficient pace to meet the Sustainable Development Goal (SDG) targets by 2030. ${ }^{1}$ At the same time, the prevalence of overweight among children and adolescents is increasing in all regions of the world. Over 38 million children under-five and 337 million children and adolescents 5-19 years of age are overweight.1,2 Communities and households with children who are overweight and obese, are some of the same communities and households with children who are undernourished. Given these multiple burdens of malnutrition, and the social and economic consequences of malnutrition for children and adolescents' health and disease risk later in life, a comprehensive set of solutions is needed to address malnutrition, in all of its forms.

In many parts of the world, many children and adolescents do not receive the diets they need - in quantity, frequency, and quality - to survive, grow, and develop to their full potential. In low- and middle-income countries, only 1 in 4 children 6-23 months achieves minimum dietary diversity for good growth and development. ${ }^{3}$ Only 1 in 6 children 6-23 months achieves a minimum acceptable diet. ${ }^{3}$ The inadequacy of children's diets continues through school-age and adolescence. For instance, nearly half of adolescent girls do not eat 3 meals a day, and many skip breakfast. ${ }^{4}$ Many adolescents consume fast foods daily, and fail to consume nutritious foods such as fruits and vegetables. ${ }^{4,5}$ Improving children and adolescents' diets remains a major challenge in the $21^{\text {st }}$ century.

Food systems are essential to delivering nutritious, safe, affordable, and sustainable diets, but the nutritional needs of children and adolescents (both of present and future generations) are often not prioritized. Though children and adolescents are an important sub-population, and some of the most vulnerable members of society, they are neglected in growing discourse about food systems. ${ }^{6}$ Actors across the food system, including food producers and suppliers, typically do not account for the nutritional needs of children and adolescents when determining what foods to grow, produce, distribute, and sell. Ultraprocessed, less nutritious foods are skilfully marketed and widely available and affordable to many, while nutritious foods are often more expensive and unaffordable. Additionally, the food environment does not lend itself to nutritious diets for children and adolescents, nor is it incentivized to do so. The consequences of our food system on the environment also impact the ability of future generations to achieve healthy diets. Actors across local, national and global food systems need to be held more accountable for providing nutritious, safe, affordable, and sustainable diets to children and adolescents today and in the future.

Children and adolescents themselves also play an important role in determining the foods that are purchased and prepared for them, and eventually consumed by them. A failure to put children and adolescents at the core of food systems fails to account for this important role that children and adolescents play in determining their own diets. It also limits potential entry points for action that might be relevant to improve the diets of children and adolescents. Many children are 
reliant on their caregivers to provide their diets. However, caregivers often respond to cues, reactions and requests from their children with regard to the foods they provide. As children and adolescents get older, they more independently shape their own food decisions. These are important characteristics and opportunities that can be leveraged to improve children and adolescents' diets.

As children and adolescents are rights holders, governments and corporations have duties and responsibilities to respect and protect those rights, including those related to food systems. ${ }^{7}$ This includes ensuring healthy and safe food production systems and food environments, as well as protecting children who are involved in the food production system. For instance, of the 152 million children engaged in child labour, nearly $71 \%$ work in agriculture. ${ }^{8}$ This makes the role of children in the food system not just an issue about nutrition, but also social protection. Putting children and adolescents at the core of food systems can better inform the ways in which we improve the diets of children and adolescents.
To this end, the United Nations Children's Fund (UNICEF) and the Global Alliance for Improved Nutrition (GAIN), in partnership with the Ministry of Foreign Affairs of the Kingdom of the Netherlands, co-hosted a global consultation on children, adolescents and food systems at the UNICEF Office of Research-Innocenti on 5-7 November 2018. The consultation brought together 60 participants from government, development partners, business, and academia from low-, middle-, and high-income settings. The consultation aimed to:

\section{Develop a common narrative} around the need for food systems to produce nutritious, safe, affordable, and sustainable diets for children and adolescents,

\section{Validate a common approach to} elucidate priority actions within the food system to improve diets of children and adolescents, and

3. Develop an action plan to improve children and adolescents' diets using a food systems approach.
This report summarizes the proceedings of the consultation and describes potential challenges and opportunities to transform the food system to improve the diets of children and adolescents now and in the future. 


\section{WHAT ARE THE AGE-SPECIFIC CHARACTERISTICS AND NUTRITIONAL NEEDS OF CHILDREN AND ADOLESCENTS?}

In preparation for the Innocenti consultation, UNICEF commissioned a series of background papers on the diets of infants and young children, school-age children, and adolescents, and on what is known about healthy diets for children. ${ }^{i}$ These are summarized below.

Children and adolescents have unique characteristics that influence their nutritional needs as they get older (Box 1), including multiple periods of rapid growth and development that result in heightened needs during early childhood and adolescence. The development of taste and food preferences are also reinforced during this time period, and very likely have implications for preferences later in life. We are not meeting children and adolescents' needs in ways that promote healthy diets, to the extent that we know what those are (Box 2).

i The background paper for children 0-4 years was prepared by Kendra Siekmans (independent consultant) and presented by Nemat Hajeebhoy (Bill and Melinda Gates Foundation) and for 10-19 years was prepared by Ty Beal (GAIN), Alison Tumilowicz (GAIN) and Saul Morris (GAIN) and presented by Saul Morris (GAIN). The background paper for healthy diets was prepared by Jenna Hollis (University of Newcastle), Claire Collins (University of Newcastle), Fabrice DeClerck (EAT), Karen McColl and Alessando Demaio (EAT) and presented by Alessandro Demaio (EAT).

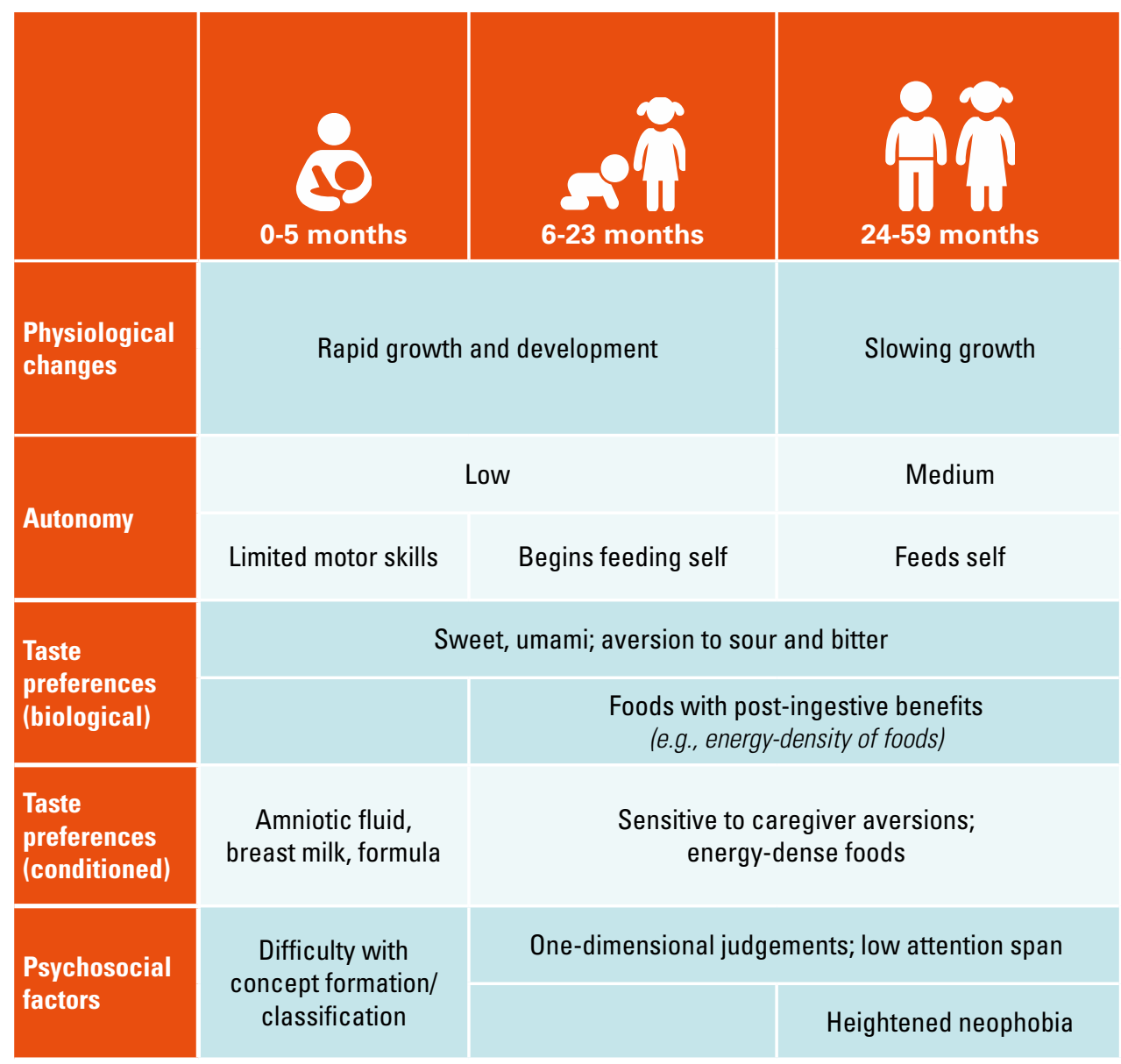

Box 1. What are the age-specific characteristics and nutritional needs of children? 


\begin{tabular}{|c|c|}
\hline 5-9 years & $15-19$ years \\
\hline $\begin{array}{l}\text { Steady linear growth, slower growth } \\
\text { compared to } 0-2 \text { years }\end{array}$ & $\begin{array}{l}\text { Rapid growth } \\
\text { (growth spurt; peak height velocity for girls) }\end{array}$ \\
\hline $\begin{array}{l}\text { Some populations may see initiation } \\
\text { of puberty at }<10 \text { years of age }\end{array}$ & $\begin{array}{c}\text { Puberty and sexual development } \\
\text { (early, delayed or extended depending on context) }\end{array}$ \\
\hline Medium & Medium \\
\hline Feeds self; increasingly self-controlled diet & $\begin{array}{l}\text { Self-controlled diet } \\
\text { (demand and decide foods based on individual preferences; reduced parental supervision) }\end{array}$ \\
\hline $\begin{array}{l}\text { Sweet, salty and sour; aversion to bitter } \\
\text { (Higher sensory threshold for sweetness) }\end{array}$ & $\begin{array}{l}\text { Less biological preference for sweet, salty and sour compared to younger children } \\
\text { (Reduced sensory sensitivity) }\end{array}$ \\
\hline $\begin{array}{l}\text { Developing taste based on what is taught by } \\
\text { caregiver; preferences reinforced by } \\
\text { what is consumed }\end{array}$ & $\begin{array}{l}\text { Self-developed taste, based on prior exposure to foods } \\
\text { Conditioned preference for low-nutrient, high-energy density foods } \\
\text { compared to high-nutrient density foods }\end{array}$ \\
\hline $\begin{array}{l}\text { Can make multidimensional judgments } \\
\text { and simultaneous considerations; able to } \\
\text { differentiate information for accuracy; } \\
\text { low attention span }\end{array}$ & $\begin{array}{l}\text { Multidimensional judgments and ability to make simultaneous considerations; } \\
\text { differentiates information about nutrition, though often does not change eating behaviours } \\
\text { ("present-oriented") }\end{array}$ \\
\hline
\end{tabular}



Birth to 2 years of age:

- Early initiation of exclusive breastfeeding within one hour of birth;

- Continued exclusive breastfeeding through the first six months of life; and

- Introduction of nutritionally adequate and safe complementary (solid) foods at 6 months together with continued breastfeeding up to 2 years of age or beyond.

\section{$\mathbf{2}$ to $\mathbf{5}$ years of age:}

- 4-5 main food groups (fruit, vegetables, grains, lean protein and dairy):

- Dietary energy increases proportionally with age, depending on age, sex and activity levels: 1400-1700 kcal/day for children 2-5 years;

- No more than $10 \%$ of total dietary energy from sugars, no more than $10 \%$ of total dietary energy from saturated fats, and no more than $1 \%$ of total dietary energy from trans fats; and

- Recommended maximum sodium intake of $2 \mathrm{~g}$ per day.

\section{5 to 9 years of age:}

- 4-5 main food groups (fruit, vegetables, grains, lean protein and dairy);

- Dietary energy increases proportionally with age, depending on age, sex and activity levels: 1500-2100 kcal/day for children 5-9 years;

- No more than $10 \%$ of total dietary energy from sugars, no more than $10 \%$ of total dietary energy from saturated fats, and no more than $1 \%$ of total dietary energy from trans fats; and

- Recommended $5 \mu \mathrm{g}$ of vitamin D, 700-1000 mg of calcium, 1.1-2 mg fluoride, and maximum sodium intake of $2 \mathrm{~g}$ per day.

\section{0 to 18 years of age:}

- 4-5 main food groups (fruit, vegetables, grains, lean protein and dairy);

- 2000-3300 kcal/day for adolescents $10-18$ years;
- $30 \%$ of total dietary energy from fat, $55-75 \%$ of dietary energy from carbohydrates, and $10-15 \%$ of dietary energy from protein;

- No more than $10 \%$ of total dietary energy from sugars, no more than $10 \%$ of total dietary energy from saturated fats, and no more than $1 \%$ of total dietary energy from trans fats; and

- For all children $>6$ months, the provision of supplementation and fortified-foods is recommended in contexts where deficiencies are prevalent, including of iron, calcium, and vitamin D.
A number of limitations exist to dietary recommendations for children and adolescents:

\section{- Food-based dietary guidelines for children and} adolescents need to be developed to capture healthy dietary patterns. Dietary guidelines for children and adolescents have historically emphasised nutrient adequacy and avoidance of certain food components (e.g., trans and saturated fat, sodium, sugar) rather than on overall dietary patterns. 'User-friendly' dietary recommendations based on foods and whole diets (and not nutrients alone) are needed, particularly for young children in the complementary feeding period (6-12 months of age).

- There is a lack of focus on healthy and sustainable eating patterns to prevent overweight and noncommunicable disease in the long-term. In particular, there are stark gaps in guidance during the complementary feeding period. During this period, dietary guidelines need to describe what foods should be consumed, as well as what foods should be limited or avoided (e.g., ultraprocessed foods and beverages). Updated guidelines for young children are expected from the World Health Organisation in 2019. Nuance is important in these guidelines, as there are major differences between low-, middle- and high-income contexts.

- There is a need for indicators aligned with dietary guidelines that measure achievement of healthy diets in children and adolescents. This includes simple indicators that proxy healthy and unhealthy dietary practices among children and adolescents (e.g. consumption of sweet snacks), as well as measures of diets themselves (e.g., calories from different food groups).

- Greater work is needed to draw consensus and ownership for children and adolescents' diets from multiple sectors. Food-based dietary guidelines should not just be from health and nutrition ministries in governments, but should also involve agriculture, education, and commerce ministries. Such a collaboration is relevant not just for achieving food security, but also for achieving healthy diets for children and adolescents. 


\section{The current state of children and adolescents" diets}

Across the continuum of early feeding practices, the vast majority of newborns, infants and young children do not receive the nutrition they need to survive and grow to reach their full potential. The complementary feeding period from 6-23 months of age is of particular concern. Young children have heightened nutrient needs during this time, and their physiology makes it difficult to meet those needs without a diverse diet..$^{10,11}$ For example, although plant-based complementary foods provide an important source of nutrients, it is difficult to meet children's nutrient requirements for iron, zinc and calcium using plant-based sources alone. As such, animal source foods are an important component of children's diets, particularly in contexts with fewer available resources. ' Dietary diversity, including consumption of animal source foods, is associated with lower risk of stunting and improved linear growth. ${ }^{12,13}$ However, consumption of animal source foods is low, particularly for infants 6-11 months. Globally, among 6-11 month olds, only $18 \%$ consume flesh foods, $11 \%$ consume eggs, and $36 \%$ consume dairy. ${ }^{14}$ Even children in the wealthiest quintiles often do not receive a minimally diverse diet. $^{3}$

\section{Diets of school-age children are also} limited in diversity, although there are large data gaps. This age group is often missing from health and nutrition surveys. From what is known, diets of school-age children in low-income settings are often characterized by nutrient-poor, monotonous plant-based diets. ${ }^{15}$ In all regions, diets of schoolage children contain limited amounts of fruits and vegetables..$^{15}$ In many of the countries in the WHO European Childhood Obesity Surveillance Initiative (2012-13), fewer than $40 \%$ of children $6-9$ years old consumed fruits and vegetables every day. ${ }^{16}$ Consumption of animal source foods was also low. Additionally, in the context of the nutrition transition, school-age children are becoming more exposed to diets high in ultra-processed foods.
The consumption of high-calorie foods among school-age children is increasingly popular, especially in urban areas.

Despite large data gaps, there is evidence indicating that adolescent diets globally are also suboptimal. There is low self-reported consumption of nutritious foods (such as dairy, meat, fruits, and vegetables), whereas consumption of energy-dense and nutrient-poor foods are commonly consumed in many settings. ${ }^{4}$ Eating patterns among adolescents are of particular concern, as reflected by skipped meals and snacking. Approximately $50 \%$ of adolescent girls eat less than 3 meals per day, and often snack at school. ${ }^{4,5}$

The foods that are consumed by adolescents contribute to suboptimal dietary patterns. In an analysis of the Global School-based Health Surveys, ${ }^{\text {ii }}$ although $66 \%$ of adolescents consumed fruit and $79 \%$ consumed

i In certain contexts, there might be other food options available for children to meet their dietary needs, without animal source foods. However, even in many high-income settings, children are not receiving adequate nutrition for their growth and development.

ii Forthcoming, based on an analysis conducted by GAIN. The Global School-based Student Health Surveys represent 254,000 school-going adolescent boys and girls from 72 countries. The majority of countries in the survey are middle-income countries in Asia, Africa and South and Central America, but the surveys represent countries from all income groups. The analysis represented data available from 2008-2015. 
vegetables at least once a day, nearly $42 \%$ drank carbonated soft drinks at least once per day and $46 \%$ consumed fast food at least once per week. The spread of fast foods is occurring in all countries, ? not just high-income, westernized countries. In conjunction with more sedentary activities (in contexts where adolescents are not involved in physical labour), frequent consumption of fast foods and sugar-sweetened beverages puts adolescents at an increased risk for over-consumption during the adolescent period.
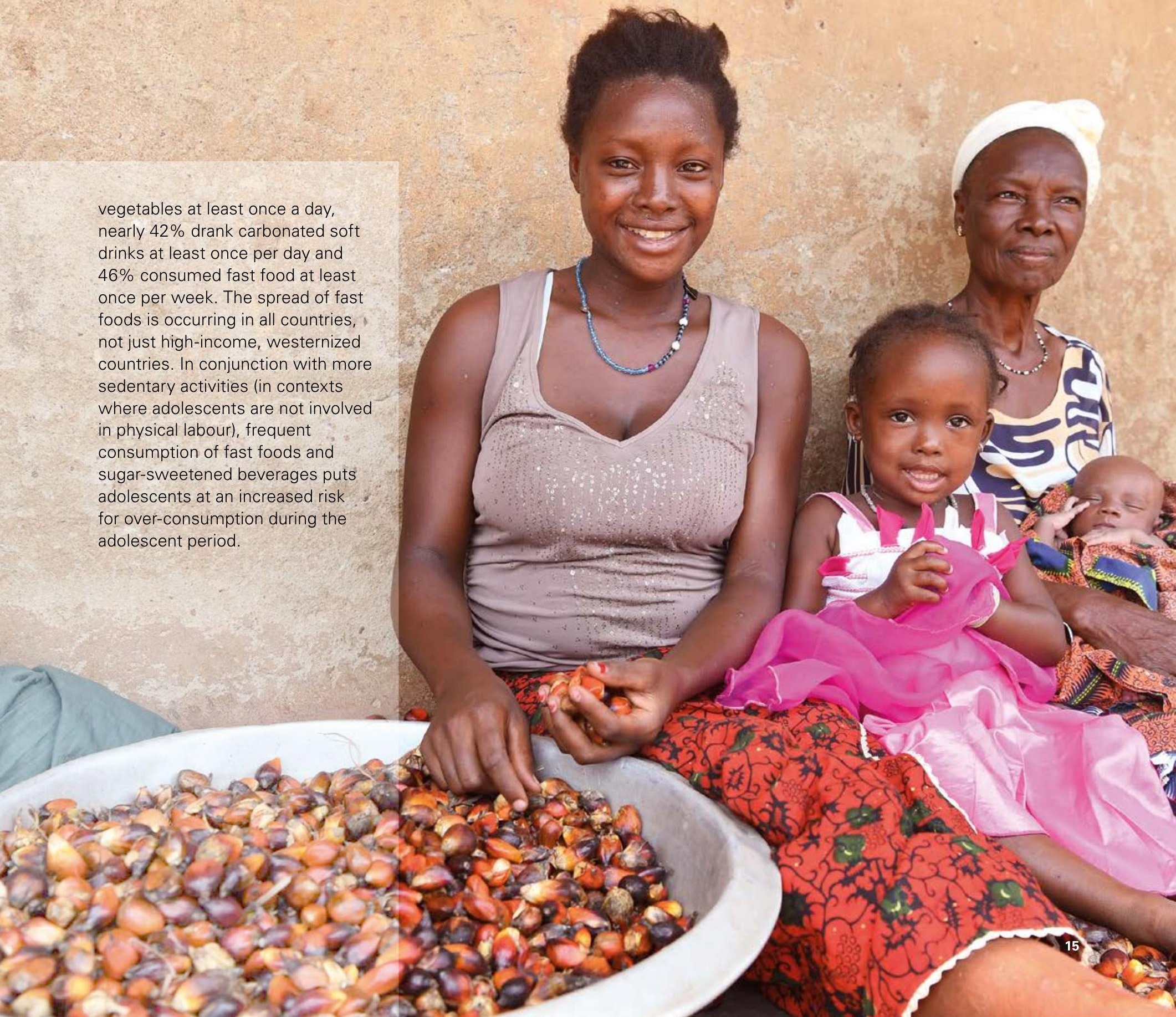

5. 


\section{WHY ARE CHILDREN AND ADOLESCENTS NOT RECEIVING THE DIETS THEY NEED FOR OPTIMAL DEVELOPMENT?}

Numerous factors influence the diets that children and adolescents receive. These include both interpersonal and socio-cultural factors (i.e., factors that represent social relationships with others and social norms), as well as economic, physical and environmental factors (i.e., factors that represent ecological relationships with a person's environment).

\section{Interpersonal and socio-cultural factors}

For many children and adolescents, their diets involve interactions with other people (e.g., parents, grandparents, siblings, friends, peers, etc.). For young children, caregivers are key gatekeepers. Caregivers decide what young children will eat, they procure and prepare those foods, and they directly feed and supervise young children when they are eating. Children's reliance on caregivers decreases as they get older and as they become more independent, whereby the influences of school staff, peers, and other role models play more of a role. ${ }^{17}$ Adolescents' food choices are strongly aligned with their broader social aspirations, and adolescents watch and model people who are important to them. ${ }^{18}$ Although this can include parents and other caregivers, it also includes peers and other social influencers. ${ }^{17}$

Personal preferences and tastes are also important factors that interact to inform what ends up on a children and adolescents' plates. Food preferences develop and are reinforced early in life. The dynamics between parents and children, including children's request for certain foods, informs what children end up eating. ${ }^{19,20}$ Permissive parenting can encourage poor dietary habits. ${ }^{21,22}$ Older children and adolescents often make decisions related to their preferences on their own, without a caregiver present. Their food decisions are more about personal likings, taste preferences, self-efficacy, and body image. ${ }^{23-26}$ These inform adolescents' dietary intake much more than adolescents' knowledge and information about food and nutrition. This has implications for the motivations of children and adolescents, and can inform how to engage with them about nutrition.

The social norms and practices of caregivers, children and adolescents also influence diets. Social beliefs about certain foods might limit their provision to young children (e.g., eggs, liver). ${ }^{27-30}$ Knowledge, skills, experience, income, and time of caregivers also limit what food is procured, prepared, and provided to children. In some settings, attention is needed to address the social norms and practices that marginalise certain groups (e.g., adolescent girls who are married and/ or pregnant) and their ability to achieve healthy diets. ${ }^{17,18}$ Additionally, with social media, the internet, and television, in addition to marketing and advertising across these platforms, social trends and norms are increasingly more global. ${ }^{17}$ Older children and adolescents are heavily exposed to media and social media, and although there are no certain impacts of this exposure on dietary behaviours, it might influence their social and food-related aspirations.

\section{Economic, physical and environmental factors}

Poverty is a key influencer for poor diets and nutritional status of children and adolescents. Irregular sources and patterns of income influence the types of foods that can be purchased for and by children and adolescents. ${ }^{18}$ Affordability of foods is key to the types of foods included in the diets of children and adolescents. ${ }^{18,30-33}$ For instance, 
calories from eggs are 6-10 times more expensive than calories from the cheapest cereals in many low-income countries (higher than many highincome countries, where egg calories are 2-3 times more expensive), and high prices are negatively associated with consumption of eggs among infants and young children. ${ }^{13,34}$ If individuals are expected to bear the cost of nutrient-dense foods, they need to be affordable, particularly for families of lower socioeconomic status.

The types of foods that are available and accessible can also adversely impact children and adolescents' diets. The foods available through markets, shops, kiosks, and vendors influence the quality of foods that caregivers can provide to children. ${ }^{35}$ If those are limited to energy-dense, nutrient-poor, ultra-processed foods and beverages, it makes it difficult for caregivers to provide healthy diets to their children. It also makes it easier for older children and adolescents to choose those foods for themselves. ${ }^{18}$ School food environments (including school feeding programmes and kiosks within schools) and the immediate environment surrounding schools are also an important shaper of dietary patterns, especially for older children and adolescents in urban areas. ${ }^{18}$ The foods available (or not available) in school food environments can limit the provision of nutritious foods and beverages to children and adolescents. Children and adolescents living in rural areas often have fewer opportunities to access foods beyond what is prepared at home or at school, and are more likely to experience seasonal food shortages. ${ }^{18}$ However, increasingly, in both rural and urban areas, there is increased availability of commercially produced, ultra-processed foods, sugar-sweetened drinks, and street foods. ${ }^{20,36}$

Marketing and advertising also facilitate suboptimal diets for children and adolescents. Marketing of ultraprocessed foods with a high content of fat, sugar and/or salt to children and adolescents remains widespread. ${ }^{37}$ The types of products, packaging, promotions, pricing, and placement of foods in retail and commercial settings, as well as by the food industry more generally, can influence the foods children and adolescents desire. ${ }^{38}$ This can further contribute to poor dietary diversity and obesogenic food environments, but can also be leveraged to promote healthy diets for children and adolescents.

\section{Summary}

Overall, in many parts of the world, many children and adolescents 0-18 years of age have suboptimal diets. Poor dietary diversity, inadequate dietary patterns, and frequent consumption of poor-quality foods, contribute to this reality. There are multiple contextual factors that contribute to the state of children and adolescents' diets, including social, economic and physical factors. Unless broader food system issues are addressed, the diets of children and adolescents will be difficult to improve. 


\section{WHAT IS A FOOD SYSTEMS APPROACH FOR CHILDREN AND ADOLESCENTS?}

Box 3. Why develop a systems framework?

- Provides a basic structure for focus and consensus of the system in its totality;

- Takes a complex system and frames it into potentially measurable components;

- Demonstrates connections and, sometimes, directionality;

- Lays out positive and negative feedback loops; and

- Illustrates continual cycles of growth, restructuring, renewal, and resilience (although difficult to capture dynamism, temporalism, and spatial nature in figures).
Food systems approaches address the direct and underlying system actors, drivers, and dynamics that affect food, people, and the planet. ' Food systems are frequently visualised in systems frameworks (Box 3). Existing frameworks conceptualise the linkages between the different components of food systems, and dietary and nutritional outcomes (as well as other outcomes - economic, environmental, social, etc.). However, most of these frameworks are not people-focused, and it is not clear where different actors sit within them.

Food systems are made up of and connected by people and are influenced by people's decisions. As such, in order to assure the diets of children and adolescents, the actions of and interactions between actors across food supply chains and food environments, as well as children, adolescents and their caregivers need to be considered. However, there are no frameworks that explicitly examine interactions between the different actors across the food system, and their influence on children and adolescents' diets.

In preparation for the consultation, a

food systems framework for children and adolescents was developed to address this gap (Figure 1). ${ }^{i}$ The framework builds on frameworks from other reports, ${ }^{39-42}$ and principally from the High-Level Panel of Experts (HLPE) report on nutrition and food systems ${ }^{6}$ and Turner, Kadiyala and colleagues' work on food environments. ${ }^{43,44}$

i According to the High-Level Panel of Experts Nutrition and Food Systems report (2017), a food system "gathers all the elements (environments, people, inputs, processes, infrastructures, institutions, etc.) and all activities that relate to the production, processing, distribution, preparation, and consumption of food, and the outputs of these activities, including socio-economic and environmental outcomes."

ii The framework was developed by Jessica Fanzo (FAO, Johns Hopkins University), Ahmed Raza (FAO) and Elizabeth Fox (Johns Hopkins University) in collaboration with Saul Morris (GAIN), Nita Dalmiya (UNICEF), Roland Kupka (UNICEF), Arnold Timmer (GAIN), and Joyce Greene (GAIN). The figure graphic was developed by Nona Reuter (UNICEF). Feedback from two rounds of external review by experts on child and adolescent nutrition, as well as feedback during the Innocenti meeting, were incorporated in this version of the framework. 


\section{The Innocenti Framework on Food Systems for Children and Adolescents}

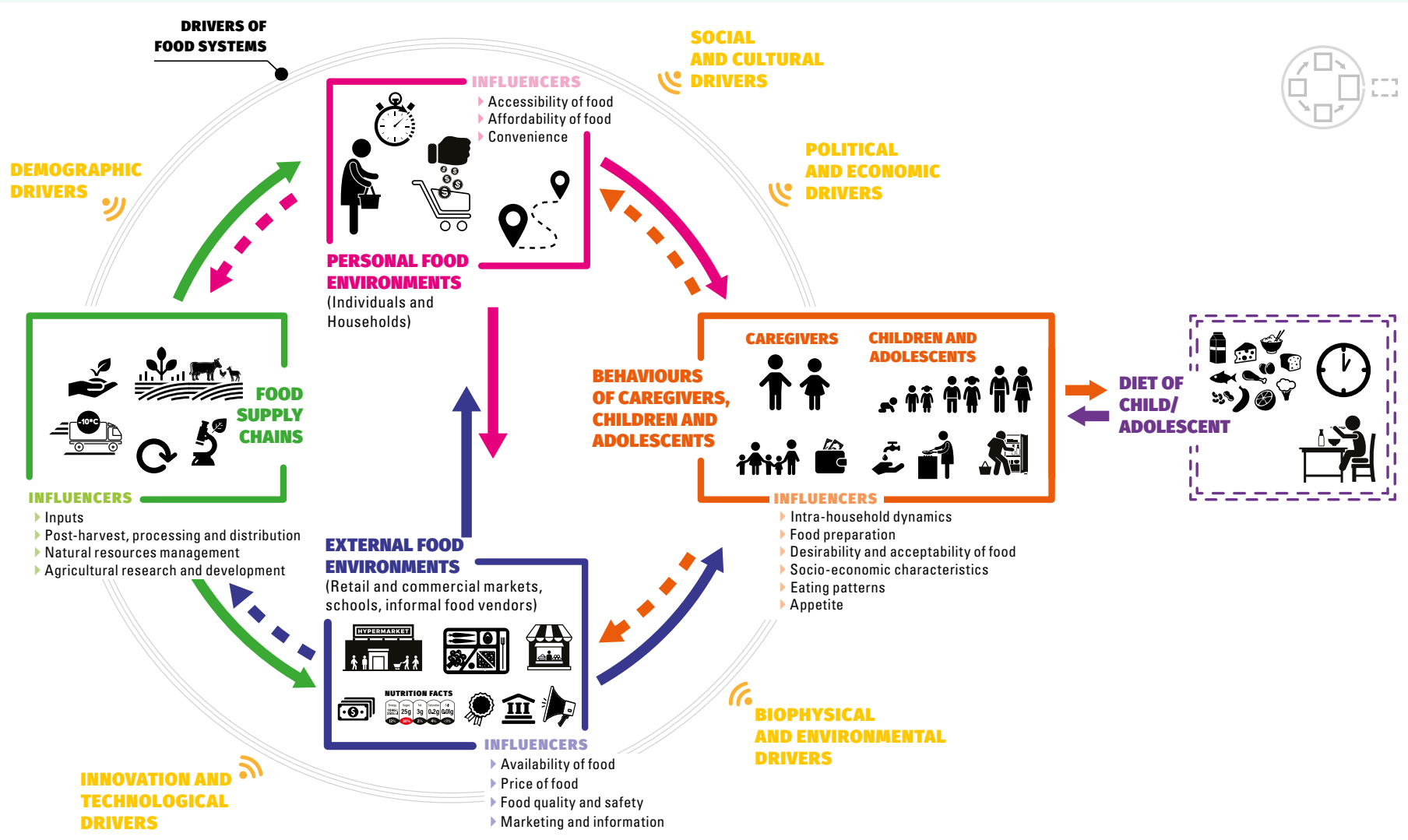

Figure 1. The Innocenti Framework on food systems for children and adolescents ${ }^{i}$

Feedback from the Innocenti meeting has been integrated into this version of the framework. 


\section{Elements of the framework}

The Innocenti Framework comprises a set of drivers, plus four determinants (food supply chains, external food environments, personal food environments, and behaviours of caregivers, children and adolescents), which together influence children and adolescents' diets (Box 4). These are described in additional detail.

\section{Box 4. Definitions related to the Innocenti Framework}

Elements of the food system are all of the drivers, determinants, influencers, and interactions represented in the food systems framework, together.

Drivers are the underlying, structural factors that impact the functionality of food systems and that need to be put in place for the food system to be able to deliver nutritious, safe, accessible, and sustainable diets.

Determinants are the processes and conditions across the food system, from production to consumption, that are necessary to improve the diets of children and adolescents. The Innocenti Framework is comprised of four determinants: food supply chains, external food environments, personal food environments, and behaviours of caregivers, children and adolescents.

Food supply chains are the actors and activities involved in food production, storage, distribution, processing, and packaging.
Food environments are the physical, economic, political, and socio-cultural context by which consumers interact with food systems to procure, prepare, and ultimately consume foods. They are separated into two complementary food environments: External and personal.

- External food environments are the retail and commercial markets, schools, and informal vendors where consumers interface with food, and reflect aspects of availability, food price, marketing and advertising, and vendor and product properties (e.g., vendor hours, food offered, etc.)

- Personal food environments are the individual and householdlevel factors that consumers bring to the food environment, such as purchasing power, access, convenience, desirability, and informs why people choose to procure the foods that they do.
Behaviours of caregivers, children, and adolescents are the procurement, preparation, supervision and eating practices of children, adolescents, and/or their caregivers.

Influencers are the more immediate and individual-level factors that determine the extent to which a determinant contributes or fails to contribute to delivering nutritious, safe, affordable, and sustainable diets.

Interactions are the linkages and feedback loops between the different determinants that indicate how different determinants positively and negatively reinforce one another.

Diets of children and adolescents are the quantity, frequency and quality of foods and drinks that children and adolescents consume, and are the outcome of the Innocenti Framework. 
Drivers are the underlying, structural factors that impact the functionality of food systems, ${ }^{6}$ and that need to be put in place for the food system to be able to deliver nutritious, safe, affordable, and sustainable diets to children and adolescents (Figure 2). The Innocenti Framework identifies the following drivers: (1) demographic drivers that reflect urbanisation, population growth, migration and forced displacement; (2) political and economic drivers that reflect political leadership, policies (e.g., economic and agricultural policies and context), as well as trade and commerce; (3) innovation and technological drivers that reflect technological and infrastructural developments and investments; (4) biophysical and environmental drivers that reflect climate change and natural resource management; and (5) social and cultural drivers that reflect the norms, traditions, and underlying social dynamics of different contexts.

\section{Drivers of food systems}

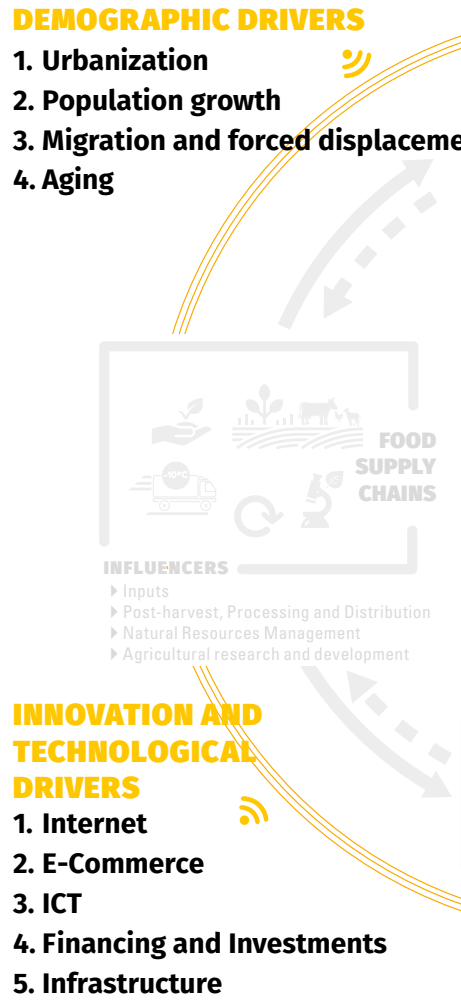

DEMOGRAPHIC DRIVERS

1. Urbanization

2. Population growth

3. Migration and forced displacement

4. Aging

5. Infrastructure

\section{SOCIAL AND CULTURAL}

\section{DRIVERS}

1. Norms, traditions, and beliefs

2. Gender equality

3. Social inclusion and dynamics

POLITICAL AND

(6. ECONOMIC DRIVERS

1. Political economy

2. Trade and markets

3. Land tenure policies and agricultural subsidies

4. Food marketing and regulations

5. Conflict and humanitarian settings

6. Employment

\section{BIOPHYSICAL}

\section{AND ENVIRONMENTAL}

\section{ro DRIVERS}

1. Natural Resources Management

2. Climate Change

3. Ecosystem Services

4. Natural Disasters

Figure 2. Drivers of food systems 


\section{Determinants and influencers of food systems}

The four determinants represent the processes and conditions in the food system, from production to consumption, that are necessary to improve the diets of children and adolescents. For each determinant, the framework identifies a set of influencers, which are the more immediate and individual-level factors that determine the extent to which a particular determinant contributes or fails to contribute to delivering nutritious, safe, affordable and sustainable diets. The influencers can be viewed as entry points for government and development partners to make the food systems more nutrition-focused.

\section{Food supply chains}

\section{Food supply chains (Figure 3)}

comprise actors and activities that play a role in taking food from production to distribution. ${ }^{6,45}$ Food supply chains can be long, and represent more than just what is produced on farms. They represent aspects of food production, storage, processing, packaging, distribution to retails and markets, and waste disposal. They also include stakeholders and activities involved in adding value to the foods that are available (i.e., 'food value chains'). This offers multiple opportunities along the different stages of the supply chain
- production, storage, distribution, processing, packaging - to maximize nutrition 'entering' and minimize nutrition 'exiting' the value chain. ${ }^{46,47}$ By developing an agriculture and food agenda that is aligned with nutrition outcomes for children and adolescents, the food supply chain can transform to not only deliver foods that taste good and are desirable to consumers, but that are also sustainable and nutritious.

At times, costs to shift and maintain production practices may be high for producers. In such instances, support to align production practices with nutritious, safe, affordable, and sustainable diets for children and adolescents cannot fall on producers alone, particularly small-scale producers. Challenges related to financing, infrastructure, land tenure, and political will are major barriers to supporting a healthy food supply. Technical assistance to support producers to develop business plans, training in quality assurance and food safety, infrastructural investments (irrigation, greenhouses, electricity, transportation), and innovations to improve efficiencies are key aspects to ensuring that producers can support their own livelihoods while at the same time ensuring production of foods to support nutritious, safe, affordable, and sustainable diets for children and adolescents (Box 5).

Public procurement strategies and investments in the public sector are important opportunities to align the food supply chain with healthy diets for children and adolescents. For instance, local procurement of foods for school feeding programmes or by locallyprocured international aid can reduce volatility for farmers and secure diets that align with child feeding guidelines and recommendations. However, in some contexts, this requires supply chain development and investment to meet quality and cost standards.

Currently, in many contexts around the world, there is a disconnect between food production and nutrition of children and adolescents. Regions of high agricultural productivity are often the same regions with high food insecurity, food safety concerns, and environmental degradation. In order to better align the food supply chain with nutrition, there is a need to focus on producing foods that contribute to nutritious, safe, affordable, and sustainable diets, particularly for children and adolescents, and to move away from an overt focus on producing greater quantities of foods, alone. 


\section{Food supply chains}

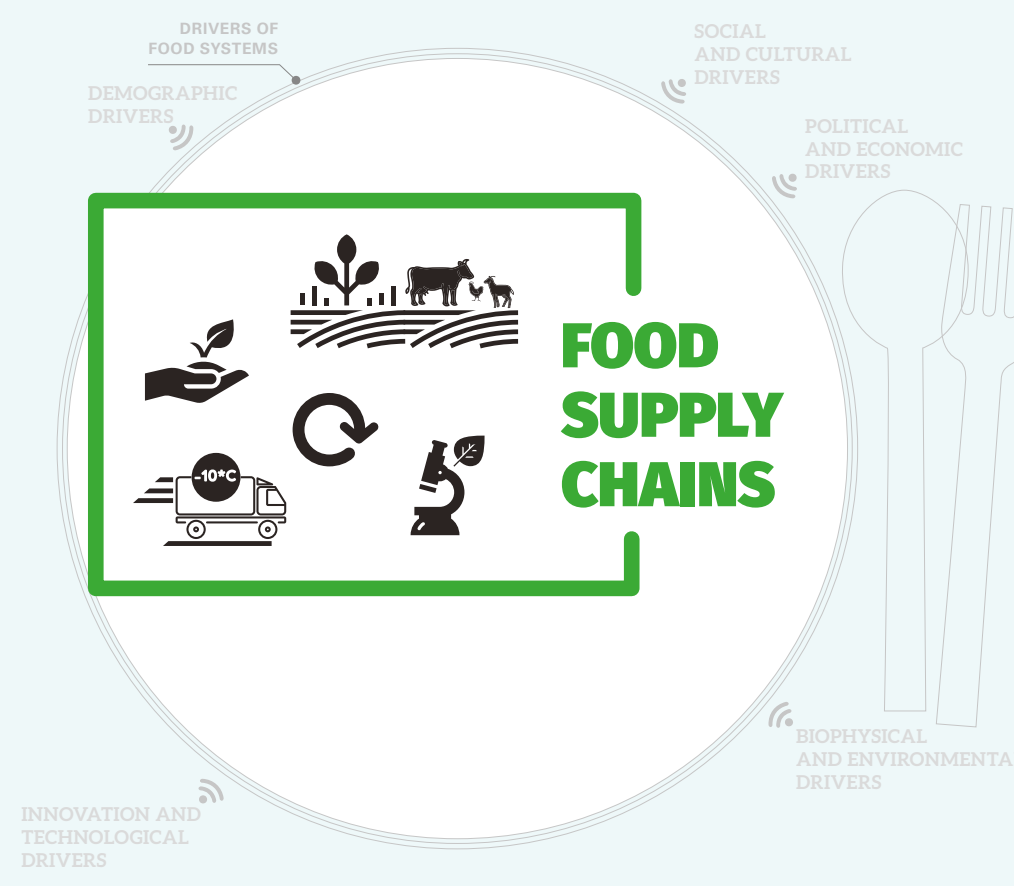

\section{INFLUENCERS}

Inputs

Access to seeds, traditional varieties, fertilizers and extension services.

Post-harvest, processing and distribution Aflatoxin control, fermentation, drying, fortification, product reformulation and storage and transport infrastructure (including cold chains), value addition

Natural resources management Soil quality, agricultural biodiversity, resilience to heat, drought, pests and diseases, water and energy use.

Agricultural research and development Innovation, entrepreneurship

Figure 3. Food supply chains and their influencers 


\section{External food environments}

Food environments refer to the physical, economic, political and sociocultural context by which consumers interact with food systems to procure, prepare, and ultimately consume food. ${ }^{6}$ This framework differentiates food environments into external food environments and personal food environments. ${ }^{43,44}$
The external food environment

(Figure 4) includes the retail and commercial markets, schools, and informal vendors, among others, where consumers interface with food. It reflects aspects related to availability, food price, marketing and advertising, and vendor and product properties (e.g., vendor hours, food offered, etc.).
Although individual consumers often have less control over their external food environment, they can influence it through demand and advocacy.
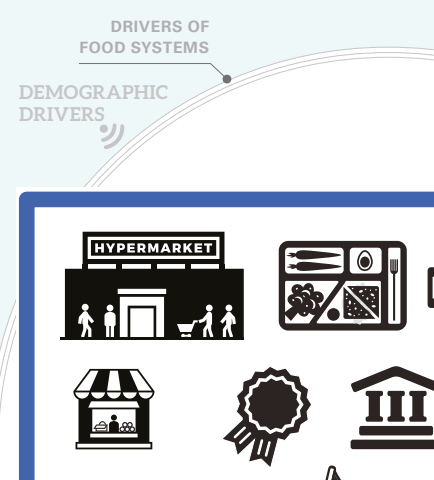

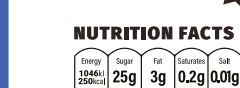

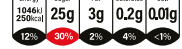

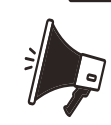

\section{(6)}

\section{EXTERIAL FOOD}

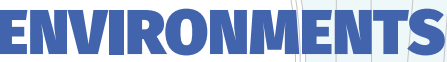

(Retail and commercial markets, schools informal food vendors)

Figure 4. External food environments and their influencers

\section{INFLUENCERS}

Availability of food

Presence of and proximity to markets

and food outlets

\section{Price of food}

Monetary value of food

Food quality and safety

Level of processing, shelf-life packaging and food composition

Marketing and information

Promotional information, branding,

advertising, sponsorship and labelling 


\section{Box 6. Successes and challenges of improving the external food environment for children in Mexico}

In Mexico, nearly one in three children are overweight or obese. ${ }^{55}$ Although trends suggest that the prevalence of overweight and obesity in Mexico is levelling off, it is still a significant public health concern given the high prevalence of children and adolescents who are affected, and the negative consequences of overweight and obesity during childhood and throughout life. ${ }^{55}$ In the context of the multiple burdens of malnutrition, Mexico has worked to improve external food environments of children through a series of joint interventions. ${ }^{56}$

\section{Taxes on sugar-sweetened beverage} (SSBs): On average, SSBs accounted for $9.8 \%$ of total energy intake in the Mexican population, and were identified as a target for lowering the intake of added sugar. ${ }^{57}$ To reduce the consumption of SSBs, the Mexican government implemented an excise tax of 1 peso/L on SSBs as of 2014 (an approximate $10 \%$ price increase based on prices in 2013). ${ }^{58}$ By increasing the price on SSBs, the average reduction of SSBs purchased was $7.5 \%$ (with a reduction of $5.5 \%$ in 2014 , and $9.7 \%$ in 2015). ${ }^{58}$ The reductions were largest for households of lower socioeconomic status. ${ }^{58}$

Warning labels: Point-of-purchase marketing, particularly to children, is common in Mexico. ${ }^{59}$ Front-ofpackage labelling is one strategy to help consumers make healthier food decisions in this context. ${ }^{60}$ Mexico uses the Daily Dietary Guideline (Guías Diarias de Alimentación, GDA) labelling system, which was developed by a group of transnational food industries. ${ }^{60}$ However, it is not wellunderstood or used by consumers. Only $23.7 \%$ of the Mexican population reads the GDA labels and only $13.8 \%$ find them to be very understandable. ${ }^{61}$ The GDA labels were less understood compared to labels from other countries. For instance, in one study, $83 \%$ of participants found the Chilean 'warning' label easy to understand compared to $54 \%$ of participants who found the Mexican GDA label easy to understand. ${ }^{62}$ Low-income populations were significantly less likely to understand and use the GDA labels. ${ }^{62}$ It is important to have labels that are easily understandable by target populations, including children, and that are developed by transparent and conflict-of-interest free groups.

\section{Government guidelines for school} environments: In 2011, the Mexican Ministry of Education and the Ministry of Health implemented national school food and beverage guidelines. These guidelines promoted physical activity and intake of fruits, vegetables and water; limited the availability of sugar-sweetened beverages and snack products; and restricted food marketing inside of schools. ${ }^{60}$ However, initiatives to improve healthy lifestyles of school-age children have been challenged by a lack of access to water fountains and safe water sources at school, interference from industry and other interest groups to proposed regulations (e.g., on proposed restrictions on energy-dense foods), and continued advertising of and access to unhealthy foods from vendors outside of schools. ${ }^{59,60,63}$ There is a need to better enforce and regulate school food environment spaces.

These examples show the opportunities and challenges of implementing policies to address overweight, obesity and noncommunicable diseases in Mexico, and across the region. Although there is increasing political visibility of the multiple burdens of disease, there are still scarce resources allocated to the control and prevention of overweight, obesity and non-communicable diseases, as well as interference from industry and interest groups in health policy and regulatory efforts. ${ }^{56}$ Tackling the multiple burdens of disease requires financial investments, sustained commitment, and action from governments, health professionals, and civil society. ${ }^{56}$ Fortunately, many existing initiatives are cost-effective and do not rely on expensive technology. Additionally, there is an opportunity to build on integrated networks in Latin America to replicate successful initiatives across the region related to schoolbased healthy eating guidelines, marketing restrictions, and physical activity. These provide promising opportunities to improve the external food environments of children in Mexico.

Developed from a presentation by Dr. Simón Barquera, Director, Nutrition Policy and Program Research Division, National Institute of Public Health (INSP), Mexico 


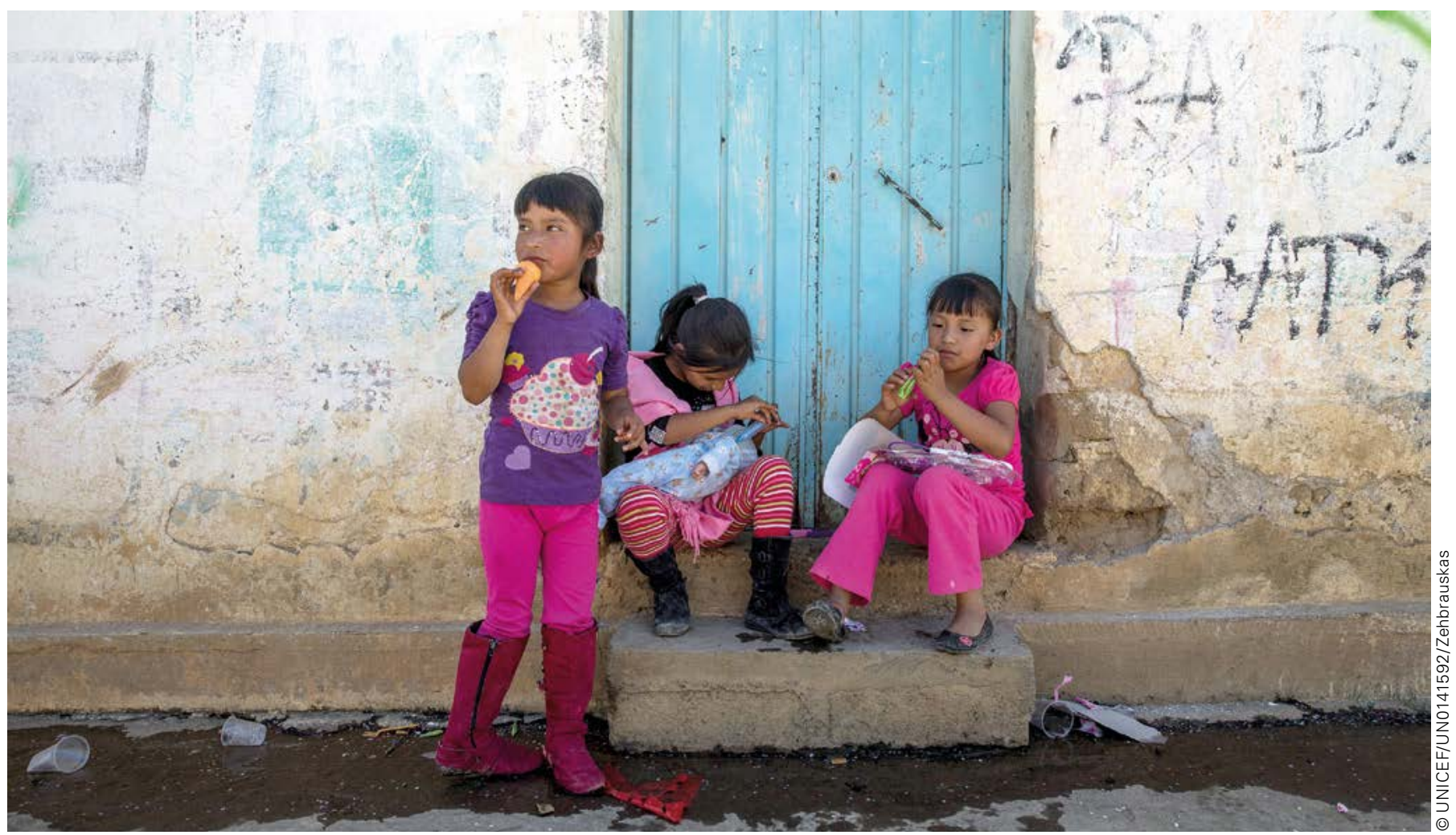

There are key differences in the external food environments, including between formal and informal food markets, that can impact the diets of children and adolescents. Despite increasing supermarket penetration, including in low- and middle-income countries (e.g., Kenya52-54), informal markets (e.g., bazaars, kiosks, street vendors) remain a key source of food for children, adolescents, and their families in low- and middle-income countries. They often provide fruits and vegetables. However, they are increasingly supplying more ultraprocessed foods high in fat, sugar and sodium (e.g., sodas, cookies, chips, crackers). There are also concerns about food safety, particularly for young children, in informal market settings. Interventions to support healthy and safe diets for children need to be adapted for the context in which food is procured, including both formal and informal settings, which might require different sets of interventions.

Regulations on the food environment are common and often stricter for children than they are for other groups, and there is still room for improvement. In some countries, highly-processed foods with warning labels cannot be marketed to children or packaged with cartoon characters. Bans on sugarsweetened beverages (including sodas and energy drinks) in public institutions such as schools are increasingly more prevalent. However, such regulations can have unintended consequences. For instance, school bans on sugarsweetened beverages and high prices of bottled water can result in children drinking water from unsafe water sources, and is associated with increased sales of sugar-sweetened beverages outside of schools, as has been seen in Mexico (Box 6). Joint interventions are needed to support healthy substitutes and alternatives for children. 


\section{Personal food environments}

Interventions that support aspects of the personal food environment need to be tied to nutrition. For instance, social protection and social safety net programmes often target affordability of foods for families. However, there is often a disconnect between these Behaviour change communication and education can be combined with programs and nutritional needs (Box 7).
Personal food environments (Figure 5) depict the individual and household level factors that consumers bring to the food environment, such as purchasing power, access, convenience and desirability, and inform why people choose to procure the foods that they do. They complement dimensions of price, availability, and vendor properties in the external food environment.
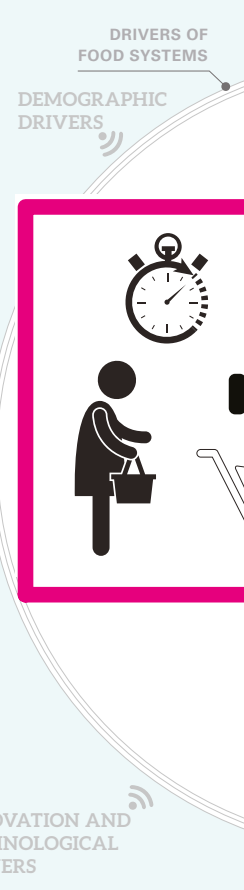

social protection programs to enhance nutrition objectives. For instance, caregivers can receive information about dietary diversity and sanitation and hygiene during health centre visits required for cash transfers. Nutritional needs of children and adolescents should also be central to reformulation of food products. Reformulation of food products that make foods more desirable and convenient should not come at the expense of nutrition, e.g., with the addition of sugar to products to enhance acceptability and desirability. Public partners and industry need to work together with consumers to ensure and advocate for nutritious foods for children and adolescents.

\section{INFLUENCERS}

Accessibility of food

Distance to nearby market and food outlets, daily mobility, mode of transport, space

PERSOINAL FOOD ENVIRONMENTS

(Individual and Households) and place

Affordability of food

Purchasing power

\section{Convenience}

Relative time and effort of preparing, cooking and consuming food and time allocation

Figure 5. Personal food environments and their influencers 


\section{Box 7. Spotlight on Ethiopia's social protection programmes}

Social protection programmes can facilitate the affordability of more nutritious foods for those most in need. In Ethiopia, the "Productive Safety Net Programme" links the social protection mechanism with the food and nutrition security agenda. However, this was not always the case. This linkage stemmed from an assessment that was completed in 2014 by the government and donors which found that cash transfers to pregnant and lactating women and mothers with young children did not result in improved nutritional status of children. ${ }^{64}$ This initiated a significant change in the programme to include explicit objectives, goals and targets related to nutrition across a number of different sectors. For instance, food packages were improved to include pulses (in addition to the oil and corn that were previously provided), public works became nutrition-sensitive, including support and actions for water, sanitation and hygiene education, such as latrine construction, information on dietary diversity, and behaviour change communication related to young child feeding at the community level by Health Extension workers. More recent evaluations have shown improvements in child nutrition outcomes for the nutritionsensitive programmes. Specifically, young children had improved dietary intakes of iron and zinc (increases in $17.7 \mathrm{mg}$ iron/ child/day and $7.4 \mathrm{mg}$ zinc/child/day). ${ }^{65}$ The integration of food and resource transfers with nutrition objectives for women and children were associated with improvements in the diets of young children in Ethiopia.

As discussed in panel presentation by Dr. Ferew Lemma, Senior Adviser, Ministry of Health, Ethiopia.

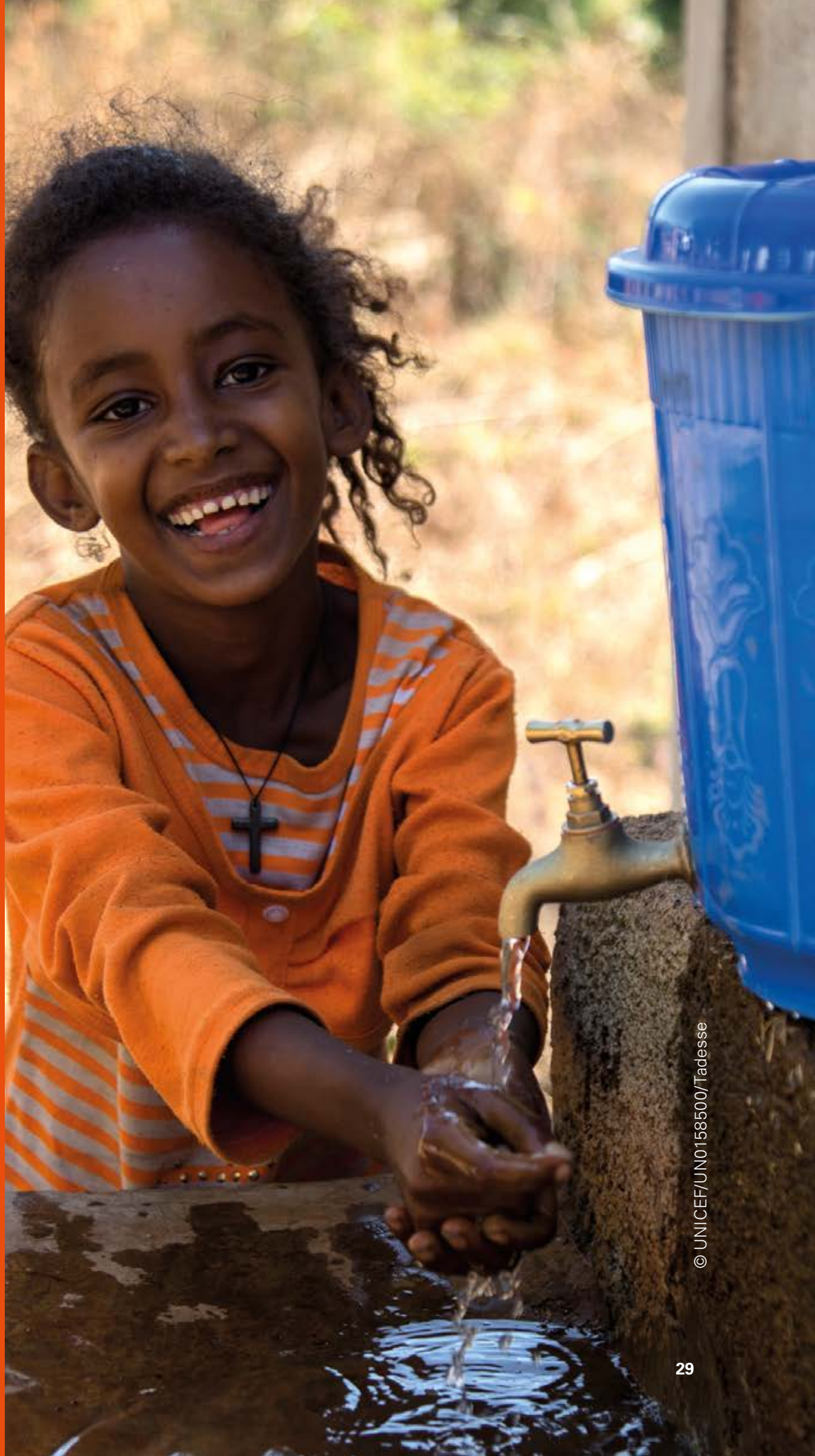




\section{Behaviours of caregivers, children and adolescents}

\author{
Behaviours of caregivers, children \\ and adolescents (Figure 6) refer to \\ the food procurement, preparation, \\ supervision, and eating practices \\ of children, adolescents and their
}

caregivers. This element is where the external and personal food environments converge, and is a buffer zone between food environments and children and adolescents' diets.

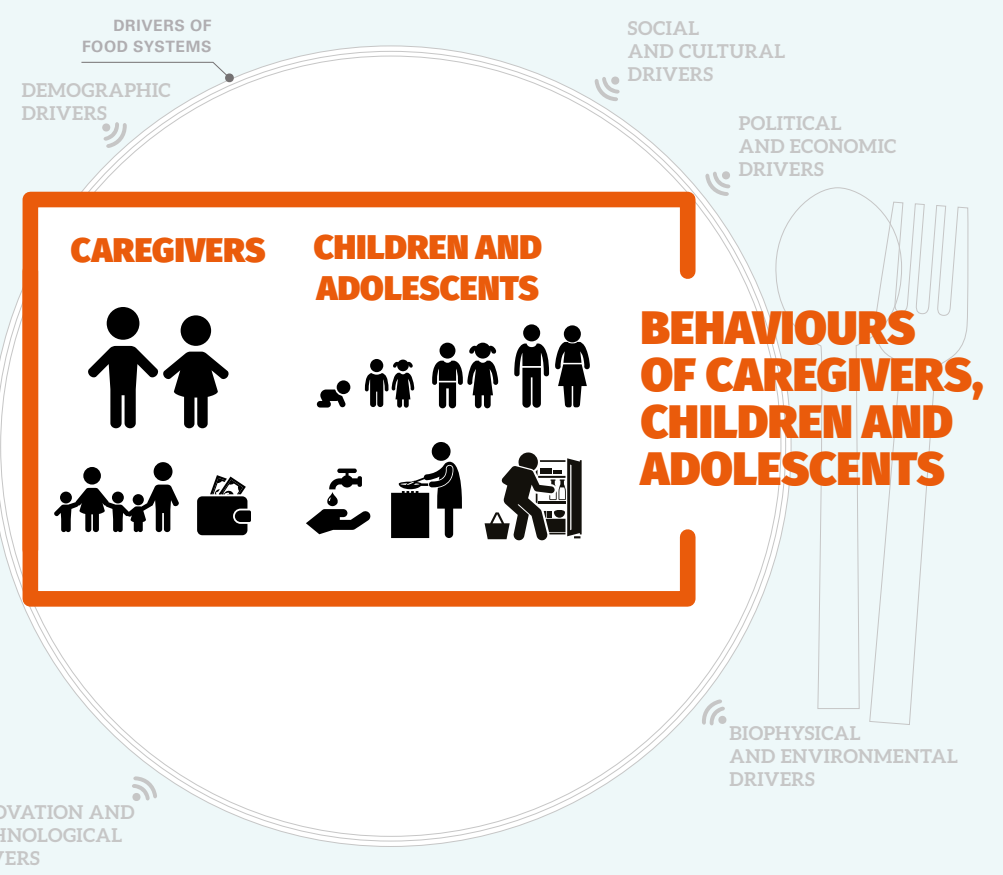

\section{INFLUENCERS}

Intra-household dynamics

Feeding and care practices, intra-household food distribution, and level of agency or control on household expenses

\section{Food preparation}

Culinary knowledge and skills, relative time and effort spent on cooking and preparing food; WASH practices

Desirability and acceptability of food Preferences, tastes, desires, attitudes, culture, social norms

\section{Socio-economic characteristics} Education and literacy

\section{Eating patterns}

Frequency, routine, pattern and quality of dietary intake, preferences, social aspects

Appetite

Incl. physical activity, energy balance

Figure 6. Behaviours of caregivers, children and adolescents and their influencers 
This element is one of the unique aspects of the framework, and demonstrates how the role of caregivers can vary across the lifespan. Caregivers are often gatekeepers for the diets of infants and children. They are responsible for procuring and preparing foods for and supervising eating practices of young children. Older children and adolescents on the other hand, are more autonomous. They do not necessarily rely on caregivers as gatekeepers. They often procure and prepare food for themselves (and, sometimes, for others in their family). This is particularly true for adolescent girls who are wives and mothers, and who prepare food for entire households. In assuming a role of procuring foods, older children and adolescents interact directly with their food environments and do not necessarily have a 'gatekeeper' outside of themselves. Interventions targeting the food provider need to consider the age of a child or adolescent when thinking about what would work best, who should be targeted, where, and how.

Interpersonal dynamics are important aspects of the behaviours of children, adolescents and caregivers. This includes caregiver-child interactions, as well as interactions with other food providers in and outside of the household. Intra-household decisionmaking power and control over household expenses is of particular concern for young women in some regions of the world who have little say in what they eat and when.

Peer pressure as well as modelling of siblings, parents and other role models, also influence the diets of older children and adolescents.

Other factors such as food preparation skills, knowledge, time, and income, in addition to desirability and acceptability, are also relevant in the foods that are procured and prepared. Information that is provided about what to feed children and adolescents needs to be consistent, frequent, and context-specific. Information should not only include what foods to eat and avoid, but also how to cook and prepare those foods. It must also account for the trade-offs caregivers, older children and adolescents face with regard to time, particularly for caregivers who work outside of the home. Information should reflect social desirability (Box 8).

Eating behaviours are the consumption practices of children and adolescents. They reflect what and how children eat, and they are influenced by children and adolescents' eating patterns, taste preferences, appetite, level of physical activity, as well as psychosocial factors that influence the foods they consume and the foods they want to consume. More information is needed on the eating patterns, taste preferences and the psychological aspects of children and adolescents' diets, and how those link back to the food system.
Box 8. Emotional demonstrations ("Emo-Demos") in East Java, Indonesia to improve infant feeding behavioursi

Snacking behaviour starts early in life. Formative research led by the GAIN and the London School of Hygiene \& Tropical Medicine, looked, amongst other issues, at the behaviours of caregivers in providing snacks to young children in East Java, Indonesia.66,67 Mothers provided snacks to their children to soothe them, particularly when the baby was crying. Often, these were unhealthy snacks of ultra-processed foods that were convenient and easy to feed. In order to improve snacking behaviours of caregivers related to the foods they provided to young children, emotional demonstrations ("emo-demos") were used to deliver key messages about snack foods during growth monitoring sessions. Emotional demonstrations are interventions that use entertainment and games to elicit emotions, in order to improve recall and increase impact. Snacks that were commonly fed to young children were mixed with hot water to elicit disgust among the caregivers in the program. Another important component of the programme was the use of the "Most Significant Change Technique," by which stories of significant change were documented. One of those was from a mother who was also a kiosk owner. After the session, she decided to stop selling the ultra-processed snacks highlighted in the growth monitoring session, and opted to sell foods that were healthy options for young children instead.

As discussed in panel presentation by Alia Poonawala, Program Lead, Better Diets for Children, GAIN. 


\section{The interactions in the food system}

Central to the framework are the arrows that connect the different determinants to one another

(Figure 7). These arrows represent interactions in the system and help to identify important feedback loops. ${ }^{71}$ For instance, the food supply chain provides the foods that are available in the food environment for consumers to purchase. Different incentives and disincentives to produce certain foods in the supply chain have an impact on the quantity, quality and price of foods that are available in the external food environment. Similarly, the demands, needs, and preferences of caregivers, children and adolescents influence and are also affected by the external food environment and the food supply chain. For example, product formulation often responds to the needs and preferences of caregivers (e.g., for convenience, taste preferences, etc.). In the other direction, the purchasing behaviours of children and their caregivers are influenced by point-of-sale advertising and promotions by food retailers.

In this way, the food system is constantly moving and shifting. Actions in one part of the food system are not isolated; different effects in one part of the system can amplify or dampen the effects in another. ${ }^{71,72}$ The arrows capture the flow of this dynamic process, and can help to anticipate (and avoid) negative unintended consequences. ${ }^{71}$ For instance, regulations to reduce sugar content in manufactured foods (e.g., sugarsweetened snacks and beverages) may result in consumer demand shifting to other substitutes that are not healthenhancing (e.g., fruit juice, beverages

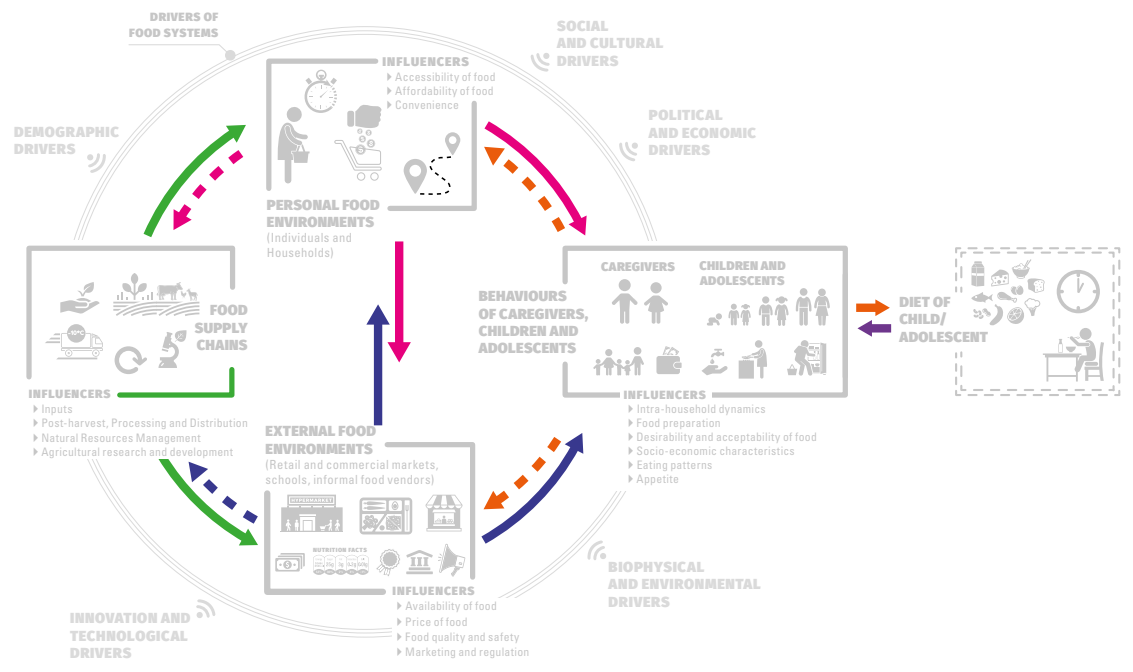

Figure 7. Arrows that connect the different determinants of the framework to one another with other sweeteners, etc.). ${ }^{73}$ Given the non-static nature of food systems and constantly changing environment, it is important to continuously develop and assess the capacity of the food system to deliver nutritious, safe, affordable and sustainable diets to children and adolescents, and the reverberating effects of actions across the food system. 


\section{Diets of children and adolescents}

The combination of elements (drivers, determinants, influencers and interactions of the framework) culminate into the quantity, frequency and quality of foods and drinks that children and adolescents consume, and are the outcome of the Innocenti Framework (Figure 8). The diets of children and adolescents feed back into the food system by influencing and reinforcing the behaviours of children, adolescents, and their caregivers as they procure, prepare, supervise, and eat foods.

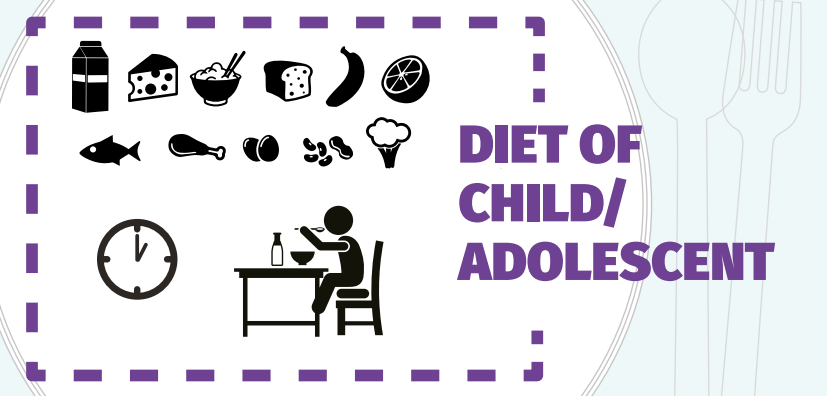

Figure 8. Diets of children and adolescents
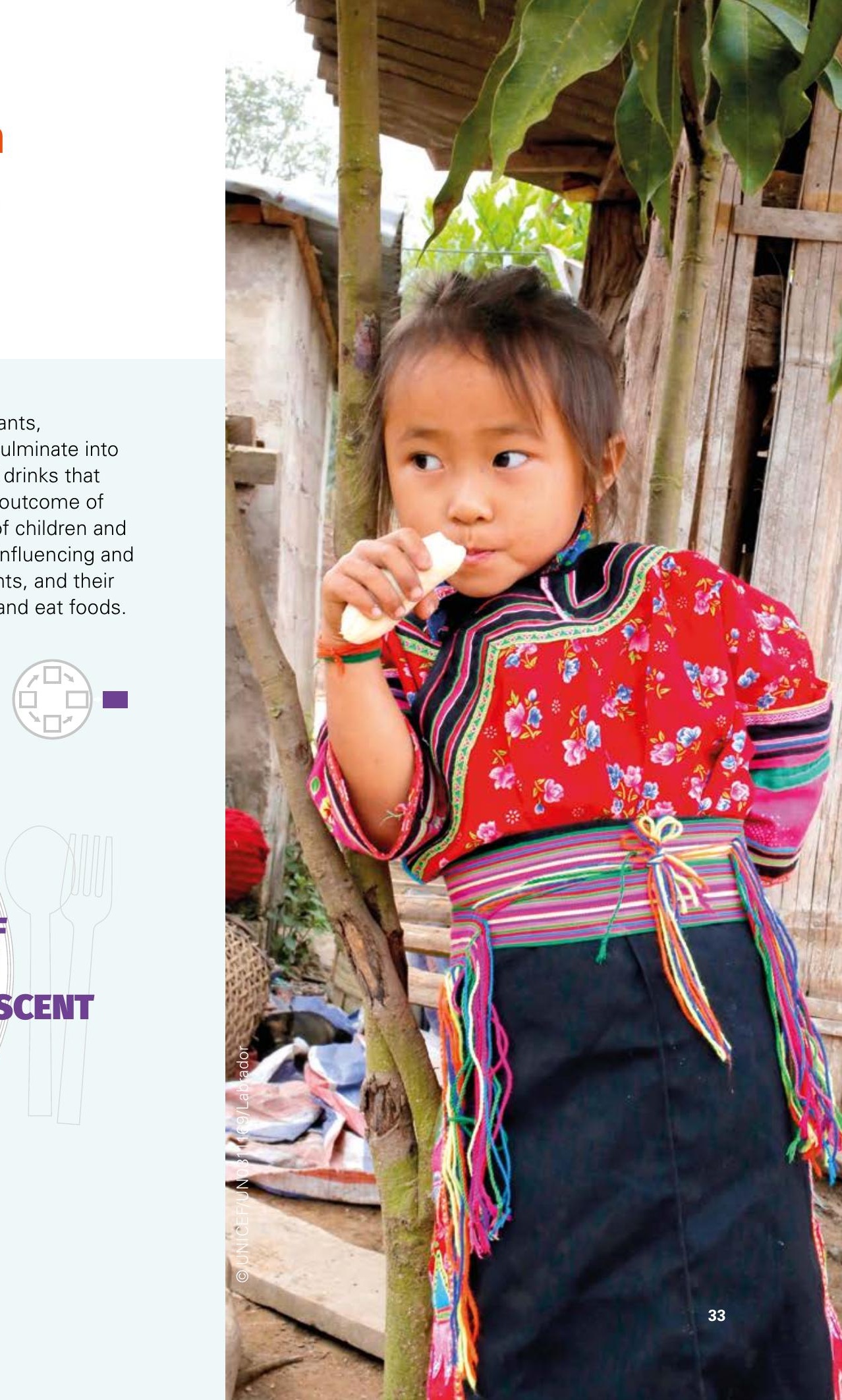


\section{HOW CAN A FOOD SYSTEMS APPROACH IMPROVE CHILDREN AND ADOLESCENTS' DIETS?}

\section{A food systems approach to improve children and adolescents' diets}

A food systems approach engages actors at all levels of the food system to reshape it and to ensure that the food system delivers nutritious, safe, affordable, and sustainable diets to all children and adolescents by securing:

- An agricultural sector that delivers food needed for healthy and affordable diets, sustainably,

- Food supply chains that deliver healthy foods in ways that are economically viable and that support decent livelihoods,

- Food environments that make healthy diets available, affordable, acceptable and appealing,

- Children and adolescents wanting and being able to eat healthy diets (and consequently, developing preferences for those diets in the long-term), and

- Children and adolescents eating healthy diets.
To reshape the food system, a systems approach needs to go beyond solely identifying actions throughout the food system. It needs to identify levers in the system that feed back into the system to amplify, impact and, subsequently, alter the system. However, as the elements of food systems and their consequences vary widely from country-to-country and within countries, levers and potential policy actions need to be context-specific (Box 9).$^{71}$

\section{Context-specific and effective policy} actions depend on the nature of the problem, the relevant food systems characteristics, and the impact on different stakeholders involved. ${ }^{71,77}$ However, with prioritisation, tradeoffs are involved. Although common overarching goals can co-exist (e.g., addressing food insecurity, environmental sustainability, and poverty $\left.{ }^{78}\right)$, specific policy actions targeting different elements of the food system are often conflicting and contradictory. ${ }^{71}$ A food systems approach to improve children and adolescents' diets helps decisionmakers align food systems actions with the goals and objectives of securing nutritious, safe, affordable and sustainable diets for children and adolescents in the long-term, and in a way that minimizes negative tradeoffs and externalities across the food system.

Gaps, needs, and opportunities

As part of the Innocenti consultation, three dietary problems were identified as examples and were illustrated in a series of case study videos (Box 10):

- Dietary Problem 1: Low consumption of animal source foods among young children

- Dietary Problem 2: Unhealthy school food environments for schoolage children

- Dietary Problem 3: Snacking and eating patterns of adolescents 


\section{Box 10. Summary of case study videos}

Videos for the case studies were produced by GAIN and can be found at <https://www.unicef.org/nutrition/foodsystems_103418.html>.

\section{Tanzania}

In the highlands of Tanzania, in Mbeya, much of the country's food is produced. The video introduces Huruma, her husband Tirion and their five children to explore who and what influences their children's nutrition. Feeding the family is a daily struggle. Huruma and Tirion own a half acre of land where they grow banana, cassava, maize and beans. They have chickens and a cow. Huruma works at a tea plantation and her husband is a day labourer working on larger farms. Huruma's children go to school without breakfast. They will get a good lunch in school, thanks to a community school feeding initiative.

Huruma has some tea and bananas before heading to work, carrying her baby - who she is exclusively breastfeeding - with her. She explains that she sells most of the cow's milk and has had to sell some chickens also. She is hoping to buy more so the children can have eggs to eat. After work, she sells some bananas from their plot and buys some vegetables and maize meal, but the family can only afford meat on special occasions. The family typically eats maize porridge and beans for their main meal in the evening. Michael, Huruma's oldest son, explains excitedly that they get to eat chicken, beef, spiced rice, and soda once a year at Christmas.

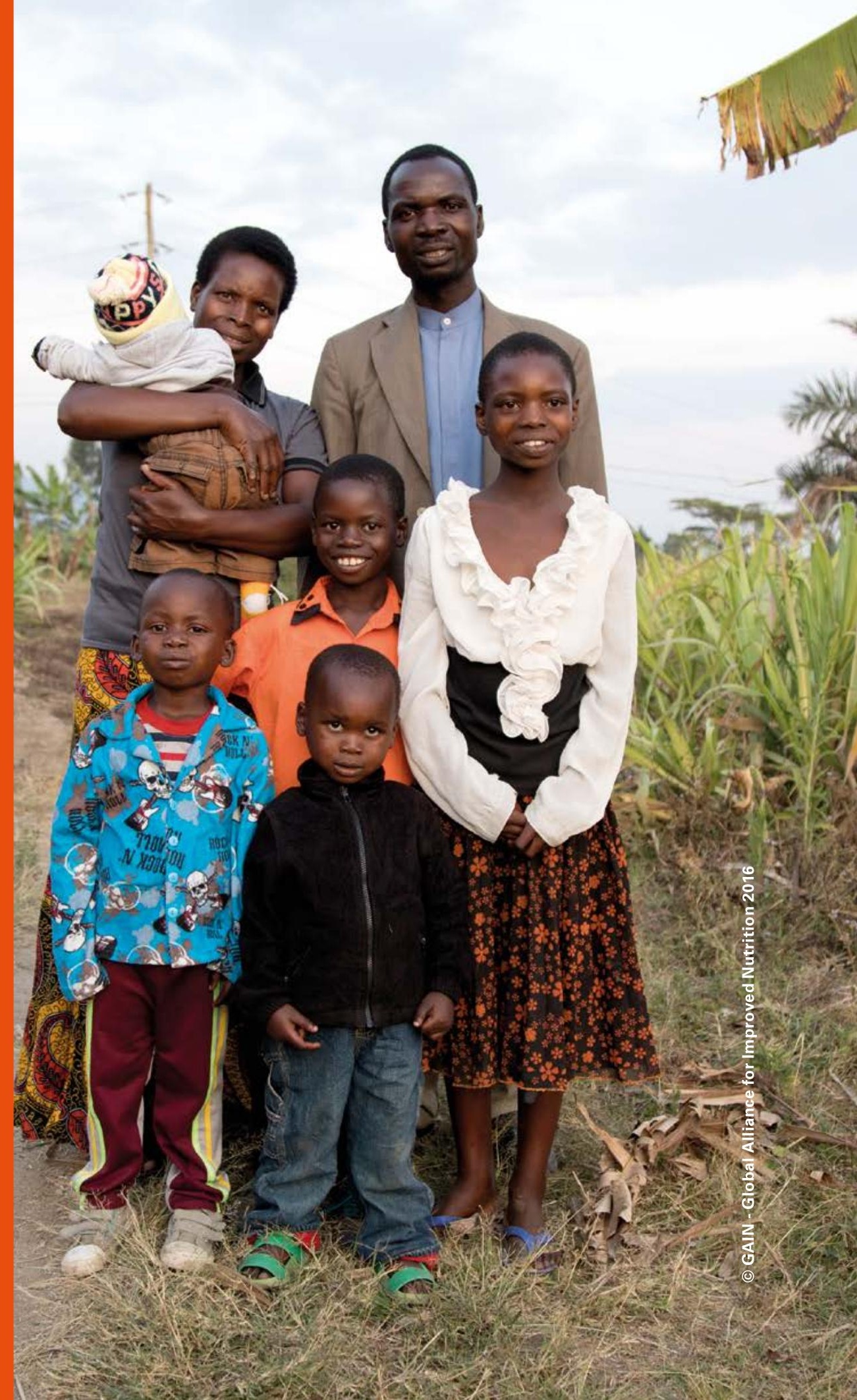




\section{Mexico}

In Toluca, a rapidly-growing urban area in greater Mexico City, there are high rates of overweight and obesity among children. The video introduces a young Tolucan family - Gabriela, her husband Erik, their six-year old son Ikal, and baby daughter Xanti to explore who and what influences their children's nutrition. At Ikal's school, healthy food and a drinking water fountain are available, but sugary snacks and drinks are sold there, and the children can choose to buy them. In Mexico, $26 \%$ of first grade children are overweight. By 6 th grade, it's up to $39 \%$.

At home, Gabriela exclusively breastfeeds her baby but reflects that this is not the case for more than two thirds of Mexican women. When the family goes out together, they see that fast foods, snacks, candy and soda drinks are available easily and marketed heavily, especially to children. Fresh fruits and vegetables are also available and inexpensive, but Gabriela explains that many Mexicans lack the time to prepare them. She also explains that children, including Ikal, constantly ask for and prefer sweet snacks and drinks. Ikal lovingly shares that the blue chewing gum flavour is his favourite.

\section{Indonesia}

In Surabaya, the second-largest city in Indonesia, there is a problem with overweight and obesity amongst children and adolescents, as in many urban areas. The video introduces Rafsi, an adolescent, his sister Marsa, and their mother in their home in an affluent suburb. Breakfast is usually the only meal the family eats together. The family eats more protein in the morning than most Indonesians. Snacks are sold outside the school. Rafsi's next meal is lunch at school, with a wide variety of foods sold by vendors. In the evening, he and his friends go to the shopping mall, where they eat dinner together and then go to a coffee shop. Rafsi and his friends know that not all the food options at the mall are healthy. Rafsi is trying to lose weight and has done so already. He knows his eating habits could improve, but it's hard to change.
Working groups were tasked with identifying immediate and underlying causes for each dietary problem, and linking those with a food systems approach to identify potential solutions and levers. The following themes emerged from the working group activities:

There is a lack of clear guidance on what diets of children and adolescents should look like.

There is a need to develop science-based national dietary guidelines. This is holding back progress and alignment of objectives of different stakeholder groups. Guidelines also need to reflect nuance to account for the multiple burdens of malnutrition in different contexts.

\section{There is a need to develop evidence-based mandatory standards for nutrition, and ways to implement and enforce those standards. Nutrition} standards for school feeding programmes and social protection programmes (e.g., food aid, food baskets) need to align with nutrition goals for children and adolescents, including with regard to food quality, food quantity, and food environments. For schools, these standards might apply to school meals, as well as snacks and beverages sold in and outside of school, and would be reflected in procurement strategies, vendor practices, marketing approaches, and education initiatives. Government and social accountability systems, as well as budget and fiscal space, are needed to implement and enforce these standards.

\section{There are missed opportunities to strengthen local supply chains to support healthy diets.} By using local supply chains for school feeding programmes, social protection schemes, and other public procurement opportunities, as well as for product formulation of processed foods, local producers can sustain their livelihoods and support production of healthy foods for children and adolescents. 


\section{Box 11. Supporting the development of a nutrition-friendly private sector in Africa}

Food systems in Africa are undergoing dynamic change and present numerous opportunities for growth. ${ }^{79}$

Small and medium enterprises (SMEs) are important stakeholders in the production, transportation, logistics, processing, retailing, and marketing of foods in these emerging economies.79-82 In sub-Saharan Africa, over $75 \%$ of fruits, vegetables, cereals, and livestock are produced by small-scale farmers ( $\leq 20$ ha). 80 Most of these fresh fruits and vegetables (FFV) stay within the domestic market, with $>90 \%$ of horticultural crops domestically marketed in the region. ${ }^{83}$ Traders, transporters, and retailers are key intermediaries in getting FFV from producers to consumers, with numerous small business owners (including women) involved in logistics and transport, as well as retail in open-air markets. ${ }^{82,83}$ An iinclusive transformation of the food system, that supports these important stakeholders along the value chain, requires public sector involvement and investment. ${ }^{79}$

Many SMEs struggle to stay afloat and grow in the African business environment. In much of Eastern and Western Africa, access to finance is identified as the single biggest obstacle to the growth of business. ${ }^{84}$ It is particularly difficult for SME business owners to secure funding because they are thought to be a risky investment. As such, existing financing mechanisms are inaccessible to mid-sized companies needing between $\$ 50,000$ and $\$ 2,000,000$ USD. Many of these companies also have limited exposure to networking opportunities, business planning support, and access to financial grants and investments. They are often unfamiliar with technical aspects of food reformulation, requirements of industry best practice, such as the Codex Alimentarius, and cost-effective modern marketing to boost demand for their products.

GAIN's Marketplace for Nutritious Foods ${ }^{85}$ is one intervention that helps SMEs access the technical and financial assistance that they need to realise their goals for their businesses. The Marketplace is not prescriptive, and is flexible to businesses' unique needs. Two participants of the program, Eric Muthomi, a business owner from Kenya, and Kota Benade, a farmer and business owner in Mozambique, shared their experiences participating in the programme during the consultation. They discussed the benefits of resources to invest in their businesses and training to develop business proposals through the Marketplace program. The resources allowed them to realise their goals, and not those of outside agencies, and have enabled them to grow their respective businesses and meet growing demands for their products.

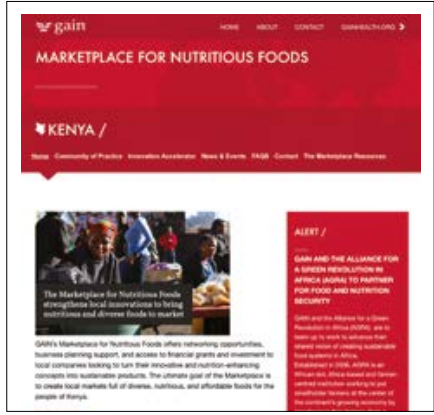

More information on GAIN's Marketplace for Nutritious Foods can be found at: https://www. gainmarketplace.com

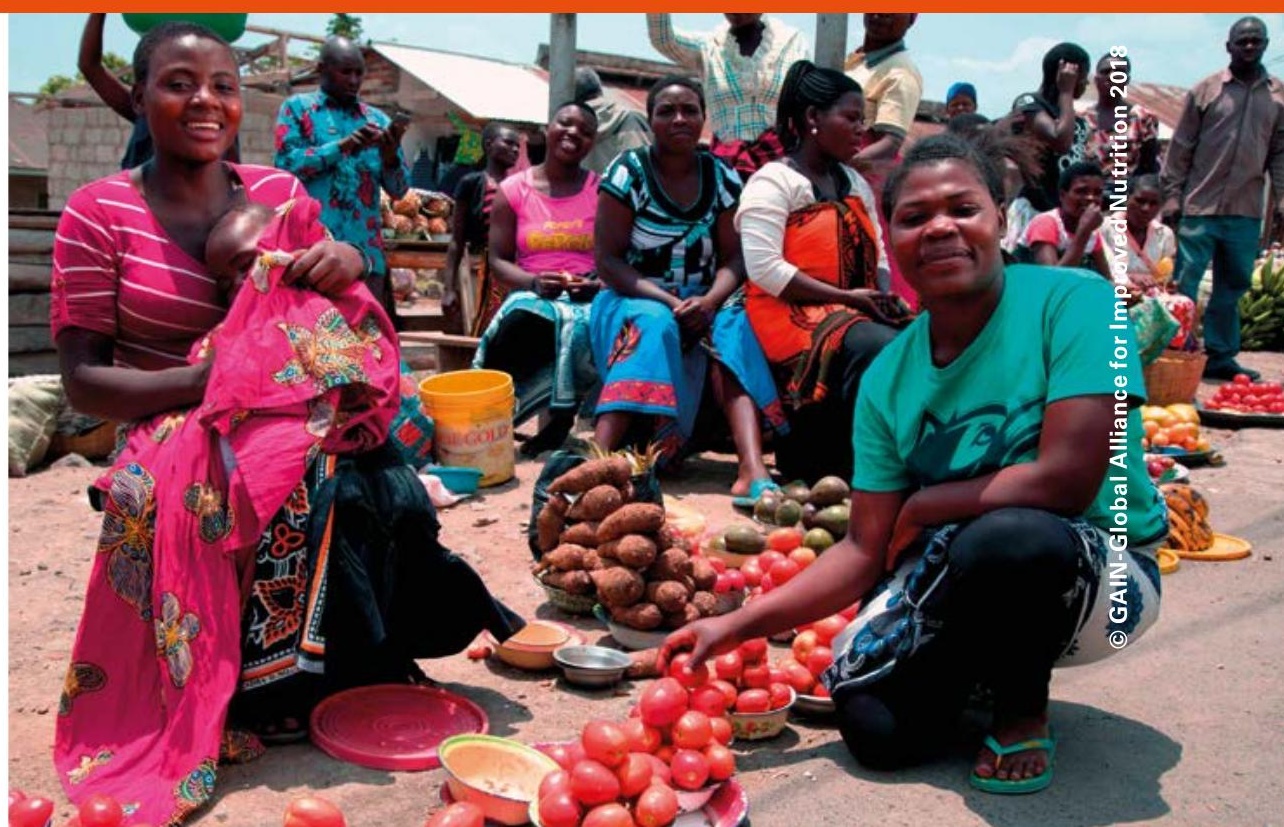




\section{Financing policies, particularly those related to agriculture, need to be more nutrition-focused.}

Small- and medium-sized enterprises need access to financing and capacitybuilding resources to support improved production of healthier and affordable food options (Box 11). Current financing schemes, such as microfinance, are not sufficient.

\section{Innovation needs to be supported along the supply chain. By}

incentivizing innovation from the private sector along the supply chain in ways that align with nutrition standards and guidelines, caregivers, children and adolescents can be given more choices, better delivery formats, and more access points for foods. Innovation can include product reformulation along the value chain (e.g., sugar reduction, or fortification with vitamins and minerals), as well as innovative technologies that improve productivity and safety of healthy, affordable foods (e.g., portable cold chains, animal housing, animal feed, etc.). High-cost production systems and value chains can result in high prices, which can be prohibitively expensive for many low-income consumers. Innovations can help to make nutrient-rich foods affordable, accessible and safe for consumers, while at the same time supporting the livelihoods of producers.

\section{There is a need for investment in infrastructure. This includes public} goods such as roads, bridges, and other infrastructural developments, as well as machinery, transportation, food preparation facilities, and potable and safe water sources for producers. This can have multiple benefits including in reducing costs for producers and improving food safety.

\section{There is a need for demand creation for healthy foods among children and adolescents, as well as their} caregivers. Childhood and adolescence are key periods in time in which values are shaped about foods. This is an opportunity. Nutrition education, sensitization, training, social media campaigns, marketing techniques, as well as economic incentives and disincentives can help to shift demand. However, initiatives need to reflect what matters to target populations. For instance, with adolescents, nutrition is not the motivating priority when they choose what foods to consume. Discussions about what is relevant to them are important in order to understand what levers can effectively motivate change.
Addressing these needs requires that the involvement and coordination of different actors be aligned with a food systems approach to improve children and adolescents' diets, as described above. This includes the involvement of numerous actors, such as governments and policymakers, standard setting agencies, investors and donors, producers, private sector actors along the value chain (including small- or medium-sized enterprises), vendors, and researchers and academics. It also involves engaging with communities, households, and consumers (including caregivers, and children and adolescents, themselves) to understand their capacities and motivations. Linkages to other systems such as education, health, finance, information, and legislation are also important as they can represent areas of tension as well as opportunity. Clear public health and nutrition objectives can inform compatible and incompatible partnerships, as well as can help hold different stakeholders accountable. 


\section{CONCLUSIONS AND NEXT STEPS}

There is an urgent need to improve the quality of diets consumed by children and adolescents worldwide. To achieve such improvements, food systems need to better respond to the nutritional needs of children and adolescents, including those who are the most marginalized. A food systems approach can identify policy and programme levers and partnerships across the food system, and can illuminate how those actions connect and reinforce one another to improve the diets of children and adolescents.

The common narrative and conceptual framework developed for the consultation, as described above, provide a starting point for advancing conversations on food systems for children and adolescents. However, in order to operationalise a food systems approach to improve children and adolescents' diets, there is a need to develop analytical tools that can guide the identification and prioritisation of contextual policy and programme actions at local and national-levels. Policy actions that reverberate across the food system, through feedback and amplification mechanisms, can positively contribute to addressing the burden of malnutrition among children and adolescents around the world.
There are a number of priorities that emerged from discussions at the consultation. Public and private sector actors at global and regional levels need to:

- Develop clear and easy to understand guidance on healthy diets for children and adolescents, to address malnutrition in all its forms;

- Develop and enforce evidencebased mandatory standards for school feeding programmes and social protection schemes that are aligned with guidelines for healthy diets of children and adolescents, including for marketing to children and adolescents;

- Define principles of engagement with private sector actors that produce food and beverages consumed by children and adolescents that seek the best interest of children and adolescents, promote accountability, and avoid conflict of interest;

- Identify the incentives and disincentives that encourage actors across food supply chains and food environments to protect, promote, and support healthy diets for children and adolescents, including support for innovation, nutrition- focused financing policies, and local procurement; and

- Determine research priorities to fill data and information gaps related to what children and adolescents eat, how they make their food decisions, what values shape those decisions, and how those food decisions vary across different social and demographic dimensions (such as rural and urban settings, differing income levels and food system typologies). Additionally, there is a need to evaluate and share findings for existing strategies to document better practices and lessons learned across the food system to improve children and adolescents' diets.

The experiences and expertise of the multiple stakeholders - those present at the consultation, in addition to in-country stakeholders and implementation partners - can help to identify actionable levers for positive change for children and adolescents in the food system. Food systems approaches have already been integrated into existing international commitments, including by the Second International Conference on Nutrition (ICN2), the UN Decade of Action on Nutrition, and the Committee on World 
Food Security. Making children and adolescents central to the food system can build on these commitments. Food systems for children and adolescents will be represented in UNICEF's State of the World's Children 2019 report (October 2019), as well as the UNICEF Nutrition Strategy 2020-2030. They are already represented by a number of programmes supported by GAIN around the world. By integrating a food systems approach for children and adolescents into global strategies, we can make food systems work better to secure nutritious, safe, affordable, and sustainable diets that support optimal growth and development in children and adolescents.

All of the materials that were developed for the consultation and represented in this report can be accessed at <https://www.unicef.org/nutrition/ food-systems.html>. Additional dissemination of findings will also occur through a peer-reviewed journal supplement (anticipated December 2019).

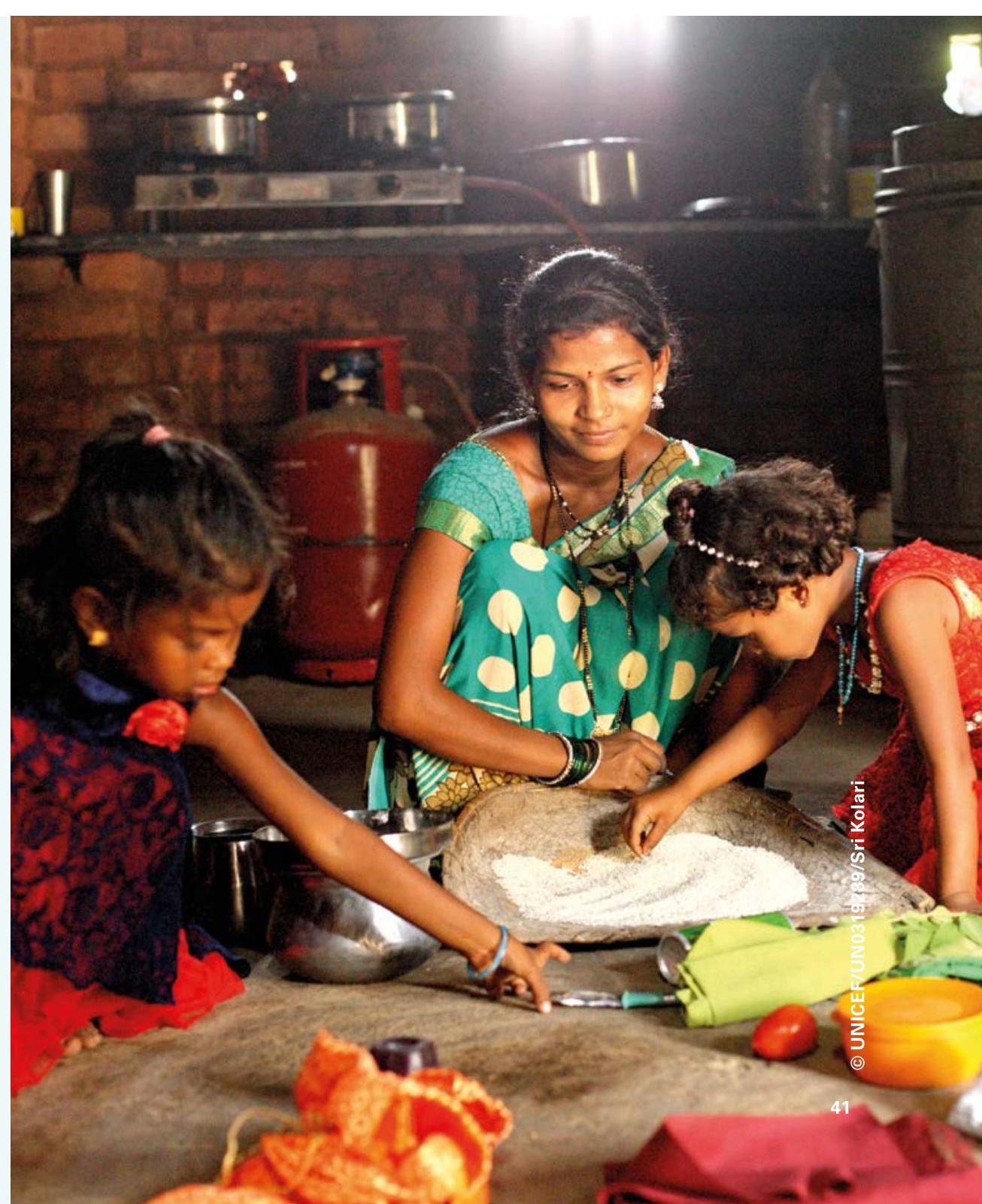




\section{LIST OF PARTICIPANTS}

\section{Victor Aguayo}

Chief, Nutrition Programme

Associate Director, Programme Division

UNICEF Headquarters, New York

\section{Khawaja Masuood Ahmed}

National Coordinator - Nutrition \&

National Fortification Alliance

Ministry of National Health Services,

$R \& C$

\section{Lise Albrechtsen}

Senior Adviser, Section for International

Development

Norwegian Ministry of Foreign Affairs

\section{Jane Badham}

Consultant

UNICEF Headquarters, New York

\section{Simon Barquera}

Executive Director

Nutrition and Health Research Center

National Institute of Public Health,

Mexico

\section{Kalpana Beesabathuni}

Global Lead - Technology \&

Entrepreneurship

Sight and Life

\section{Kota Benade}

Vegetable producer

\section{Christophe Béné}

Senior Policy Expert

CIAT Sustainable Food System Initiative

\section{Francesco Branca}

Director, Department of Nutrition for Health and Development

World Health Organization

\section{Alison Cairns}

Director, FReSH

World Business Council for Sustainable

Development

\section{Nita Dalmiya}

Nutrition Specialist, Nutrition Section UNICEF Headquarters, New York

\section{Alessandro DeMaio}

CEO

EAT Forum

\section{Kathrin Demmler}

Research Associate

Malabo Montpellier Panel, Centre for

Environmental Policy

Imperial College London

\section{Juliano Diniz De Oliveira}

Policy Specialist

The State of the World's Children Report

\section{Shauna Downs}

Assistant Professor, Dept. of

Health Systems and Policy

Rutgers School of Public Health

\section{Rafael Fabrega}

Director

Tetra Laval Food for Development Tetra Pak Inc.

\section{Jessica Fanzo}

Senior Nutrition and Food Systems Officer

Food and Agriculture Organization of the United Nations (FAO)

\section{Elizabeth Fox}

Postdoctoral Research Fellow Berman Institute of Bioethics Johns Hopkins University

\section{Joyce Greene}

Consultant, Fortification Advocacy and Fundraising

Global Alliance for Improved Nutrition

\section{Bernadette Gutmann}

Corporate Alliances Specialist,

Children's Rights and Business

UNICEF Geneva

\section{Nemat Hajeebhoy}

Deputy Director, Country Impact Bill \& Melinda Gates Foundation 


\section{Carolyn Hart}

Vice President, International Division John Snow, Inc

\section{Corinna Hawkes}

Director, Centre for Food Policy

City University of London

\section{Jo Jewell}

Technical Officer

World Health Organization Regional

Office for Europe

\section{Suneetha Kadiyala}

Associate Professor in Nutrition-

Sensitive Development

London School of Hygiene and Tropical

Medicine

\section{Inge Kauer}

Executive Director

The Access to Nutrition Index (ATNI)

\section{Brian Keeley}

Editor, The State of the World's Children

Report

UNICEF New York

\section{Knut-Inge Klepp}

Norwegian Health Directorate

Government of Norway

\section{Roland Kupka}

Senior Adviser Nutrition

UNICEF Headquarters, New York

\section{Lauren Landis}

Director of Nutrition

World Food Programme

\section{Ferew Lemma}

Senior Advisor

Ministry of Health, Ethiopia

\section{Frances Mason}

Senior Nutrition Adviser

Save the Children UK

\section{Arlene Mitchell}

Executive Director

Global Child Nutrition Foundation

\section{Saul Morris}

Director of Programme Services

Global Alliance for Improved Nutrition

\section{William Moore}

Executive Director

The Eleanor Crook Foundation

\section{Enock Musinguzi}

Country Director, Tanzania

Global Alliance for Improved Nutrition

\section{Eric Muthomi}

Director

Stawi Foods, Kenya

\section{Obey Assery Nkya}

Director, Coordination of Government Business

Prime Minister's Office, Tanzania

\section{Stineke Oenema}

Coordinator

United Nations System Standing

Committee on Nutrition

\section{Ellen Piwoz}

Senior Program Officer, Nutrition Division of Global

Development Program

Bill \& Melinda Gates Foundation

\section{Alia Poonawala}

Program Lead, Better Diets for Children Global Alliance for Improved Nutrition

\section{Ahmed Raza}

Nutrition and Food Systems Officer Food and Agriculture Organization of the United Nations (FAO)

\section{Christiane Rudert}

Regional Adviser, Nutrition

UNICEF East Asia \& Pacific Regional Office 


\section{Marie Ruel}

Director, Poverty, Health and Nutrition

Division

International Food Policy Research

Institute

\section{Abdul Sami}

Assistant Director (R\&D)

Punjab Food Authority, Lahore, Pakistan

\section{Rutger Schilpzand}

Managing Director

Choices International: Healthy Food

Choice Initiatives

\section{Aya Shneerson}

Senior Food Security Offices

World Food Programme; CFS

Secretariat

\section{Lucy Sullivan}

Executive Director

Thousand Days

\section{Shelly Sundberg}

Senior Program Offices

Bill \& Melinda Gates Foundation

\section{Arnold Timmer}

Director, Consumer Nutrition

Global Alliance for Improved Nutrition

\section{Tom Tomich}

Professor \& Director,

Agricultural Sustainability Institute

UC Davis

\section{David Tschirley}

Professor, International Development Michigan State University

\section{Alison Tumilowicz}

Senior Technical Advisor, Monitoring, Learning and Research

Global Alliance for Improved Nutrition

\section{Qaiser Munir Pasha}

Country Director, Pakistan

Global Alliance for Improved Nutrition

\section{Cindy van den Boom}

Senior Policy Officer

Netherlands Ministry of Foreign Affairs

\section{Ria van Der Maas}

Global Nutrition and Health Manager Unilever

\section{Frits van der Wal}

Senior Policy Adviser, Food and

Nutrition Security

Netherlands Ministry of Foreign Affairs

\section{Laura Wellesley}

Senior Policy and Advocacy Adviser

UNICEF UK

\section{Fokko Wientjes}

Vice President Nutrition in

Emerging Markets \& Food Systems

Transformation

DSM

\section{Amirhossein Yarparvar}

Regional Health and Nutrition Specialist UNICEF Europe and Central Asia

Regional Office 


\section{References}

1. United Nations Children's Fund, World Health Organization, World Bank Group. Levels and trends in child malnutrition: Key findings of the 2018 Edition of the Joint Child Malnutrition Estimates. New York, Geneva, and Washington DC: UNICEF/WHO/World Bank, 2018. Available at <https://data.unicef. org/resources/levels-and-trends-in-childmalnutrition-2018/>.

2. NCD Risk Factor Collaboration (NCD-RisC). Worldwide trends in body-mass index, underweight, overweight, and obesity from 1975 to 2016: A pooled analysis of 2,416 population-based measurement studies in 128.9 million children, adolescents, and adults. Lancet 2017; 390(10113): 2627-42.

3. United Nations Children's Fund (UNICEF) Division of Research and Policy. UNICEF Global Databases: Infant and Young Child Feeding. New York, 2018. Available at $<$ https://data.unicef.org/topic/nutrition/ infant-and-young-child-feeding/>.

4. Keats EC, Rappaport Al, Jain R, Oh C, Shah $S$, Bhutta ZA. Diet and eating practices among adolescent girls in low- and middleincome countries: A systematic review. Arlington: Strengthening Partnerships, Results, and Innovations in Nutrition Globally (SPRING), 2018. Available at <https://www. spring-nutrition.org/sites/default/files/ publications/reports/spring_diet_eating_ adol_girls_Imic.pdf $>$.

5. Keats EC, Rappaport Al, Shah S, Oh C, Jain $\mathrm{R}$, Bhutta ZA. The dietary intake and practices of adolescent girls in low- and middle-income countries: A systematic review. Nutrients 2018; 10(12): 1978.

6. High Level Panel of Experts on Food Escurity and Nutrition. Nutrition and food systems. A report by the High Level Panel of Experts on Food Security and Nutrition of the Committe on World Food Security. Rome: Food Agriculture Organization, 2017. Available at <http://www.fao.org/3/a-i7846e.pdf>
7. United Nations Children's Fund (UNICEF). A child rights-based approach to food marketing: A guide for policy makers. New York: UNICEF, 2018. Available at <https://www.unicef.org/ csr/files/A_Child_Rights-Based_Approach_ to_Food_Marketing_Report.pdf $>$.

8. International Labour Organisation (ILO). Global estimates of child labour: Results and trends 2012-2016. Geneva: International Labour Office, 2017. Available at <https:// www.ilo.org/global/publications/books/ WCMS_575499/lang--en/index.htm>

9. World Health Organisation (WHO). Healthy diet. Fact Sheet No 394. Geneva: WHO 2018. Available at <https://www.who. int/en/news-room/fact-sheets/detail/ healthy-diet>.

10. Dewey KG. The challenge of meeting nutrient needs of infants and young children during the period of complementary feeding: An evolutionary perspective. J Nutr 2013; 143(12): 2050-4.

11. Dewey KG, Bitta BS. Strategies for ensuring adequate nutrient intakes for infants and young children during the period of complementary feeding. A\&T Technical Brief, Issue 7. Washington, DC: Alive \& Thrive, 2013. Available at $<$ https://www.aliveandthrive. org/wp-content/uploads/2018/07/InsightIssue-7_Ensuring-Adequate-Nutrition.pdf $>$.

12. Krasevec J, An X, Kumapley R, Begin F, Frongillo EA. Diet quality and risk of stunting among infants and young children in low- and middle-income countries. Matern Child Nutr 2017; 13 Suppl 2.

13. Headey D, Hirvonen K, Hoddinott J. Animal sourced foods and child stunting. Amer J Agr Econ 2018; 100(5): 1302-19.

14. White JM, Begin F, Kumapley R, Murray C, Krasevec J. Complementary feeding practices: Current global and regional estimates. Matern Child Nutr 2017; 13 Suppl 2.

15. Ochola S, Masibo PK. Dietary intake of schoolchildren and adolescents in developing countries. Ann Nutr Metab 2014; 64 Suppl 2: 24-40.
16. World Health Organisation (WHO). WHO European Childhood Obesity Surveillance Initiative: Overweight and obesity among 6-9-year-old children. Report of the third round of data collection 2012-2013. Copenhagen: WHO European Chldhood Obesity Surveillance Initiative, WHO Regional Office for Europe., 2018. Available at <http:// www.euro.who.int/_data/assets/pdf_ file $/ 0010 / 378865 /$ COSI-3.pdf?ua $=1>$.

17. Patton GC, Sawyer SM, Santelli JS, et al. Our future: A Lancet Commission on adolescent health and wellbeing. Lancet 2016; 387(10036): 2423-78.

18. Anthrologica, World Food Programme (WFP) Bridging the Gap: Engaging adolescents for nutrition, health and sustainable development. Rome: World Food Programme, 2018. Available at <https://www.wfp.org/ content/2018-bridging-gap-engagingadolescents-nutrition-health-andsustainable-development>

19. Mazarello Paes V, Ong KK, Lakshman R. Factors influencing obesogenic dietary intake in young children (0-6 years): Systematic review of qualitative evidence. BMJ Open 2015; 5(9): e007396-e.

20. Pries AM, Huffman SL, Champeny M, et al. Consumption of commercially produced snack foods and sugar-sweetened beverages during the complementary feeding period in four African and Asian urban contexts. Matern Child Nutr 2017; 13 Suppl 2.

21. Verloigne M, Van Lippevelde W, Maes L, Brug J, De Bourdeaudhuij I. Family- and school-based correlates of energy balancerelated behaviours in 10-12-year-old children: A systematic review within the ENERGY (EuropeaN Energy balance Research to prevent excessive weight Gain among Youth) project. Public Health Nutr 2012; 15(8): 1380-95.

22. Verstraeten $\mathrm{R}$, Leroy $\mathrm{JL}$, Pieniak $\mathrm{Z}$, et al. Individual and environmental factors influencing adolescents' dietary behavior in low- and middle-income settings. PLoS One 2016; 11(7): e0157744. 
23. McClain AD, Chappuis C, Nguyen-Rodriguez ST, Yaroch AL, Spruijt-Metz D. Psychosocial correlates of eating behavior in children and adolescents: A review. Int J Behav Nutr Phys Act 2009; 6: 54

24. Banna JC, Buchthal OV, Delormier T, CreedKanashiro HM, Penny ME. Influences on eating: A qualitative study of adolescents in a periurban area in Lima, Peru. BMC Public Health 2016; 16: 40

25. Becker AE, Burwell RA, Gilman SE, Herzog DB, Hamburg P. Eating behaviours and attitudes following prolonged exposure to television among ethnic Fijian adolescent girls. Br J Psychiatry 2002; 180: 509-14.

26. Karimi-Shahanjarini A, Omidvar N, Bazargan M, Rashidian A, Majdzadeh R, Shojaeizadeh D. Iranian female adolescent's views on unhealthy snacks consumption: A qualitative study. Iran J Public Health 2010; 39(3): 92-101.

27. Iannotti LL, Lutter CK, Bunn DA, Stewart CP. Eggs: The uncracked potential for improving maternal and young child nutrition among the world's poor. Nutr Rev 2014; 72(6): 355-68.

28. Meyer-Rochow VB. Food taboos: Their origins and purposes. J Ethnobiol Ethnomed 2009; 5: 18 -

29. Lutter CK, lannotti LL, Stewart CP. The potential of a simple egg to improve maternal and child nutrition. Matern Child Nutr 2018; 14(S3): e12678.

30. Pachon H, Simondon KB, Fall ST, et al. Constraints on the delivery of animal-source foods to infants and young children: Case studies from five countries. Food Nutr Bull 2007; 28(2): 215-29.

31. Armar-Klemesu M, Osei-Menya S, ZakariahAkoto S, Tumilowicz A, Lee J, Hotz C. Using ethnography to identify barriers and facilitators to optimal infant and young child feeding in rural Ghana: Implications for programs. Food Nutr Bull 2018; 39(2): 231-45.

32. Burns J, Emerson JA, Amundson K, Doocy S, Caulfield LE, Klemm RD. A qualitative analysis of barriers and facilitators to optimal breastfeeding and complementary feeding practices in South Kivu, Democratic Republic of Congo. Food Nutr Bull 2016; 37(2): 119-31.
33. Darmon N, Drewnowski A. Contribution of food prices and diet cost to socioeconomic disparities in diet quality and health: $A$ systematic review and analysis. Nutr Rev 2015; 73(10): 643-60

34. Morris SS, Beesabathuni K, Headey D. An egg for everyone: Pathways to universal access to one of nature's most nutritious foods. Matern Child Nutr 2018; 14 Suppl 3: e12679.

35. Popkin BM. Nutrition, agriculture and the global food system in low and middle income countries. Food Policy 2014; 47: 91-6.

36. Ford ND, Patel SA, Narayan KM. Obesity in low- and middle-income countries: Burden, drivers, and emerging challenges. Annu Rev Public Health 2017; 38: 145-64.

37. Kelly B, Halford JCG, Boyland EJ, et al. Television food advertising to children: A global perspective. Am J Public Health 2010; 100(9): 1730-6.

38. Boyland EJ, Nolan S, Kelly B, et al. Advertising as a cue to consume: A systematic review and meta-analysis of the effects of acute exposure to unhealthy food and nonalcoholic beverage advertising on intake in children and adults. Am J Clin Nutr 2016; 103(2): 519-33.

39. Sobal J, Khan LK, Bisogni C. A conceptual model of the food and nutrition system. Soc Sci Med 1998; 47(7): 853-63.

40. Ericksen PJ. Conceptualizing food systems for global environmental change research. Glob Environ Change 2008; 18(1): 234-45.

41. Lawrence MA, Friel S, Wingrove K, James SW, Candy S. Formulating policy activities to promote healthy and sustainable diets. Public Health Nutr 2015; 18(13): 2333-40.

42. Mozaffarian D. Dietary and policy priorities for cardiovascular disease, diabetes, and obesity A comprehensive review. Circulation 2016; 133(2): 187-225

43. Turner $\mathrm{C}$, Aggarwal A, Walls $\mathrm{H}$, et al. Concepts and critical perspectives for food environment research: A global framework with implications for action in low- and middle-income countries. Glob Food Sec 2018; 18: 93-101.
44. Turner C, Kadiyala S, Aggarwal A, et al. Concepts and methods for food environment research in low and middle income countries. Agriculture, Nutrition and Health Academy Food Environments Working Group (ANHFEWG). London: Innovative Methods and Metrics for Agriculture and Nutrition Actions (IMMANA) programme, 2017. Available at <https://anh-academy.org/sites/default/ files/FEWG_TechnicalBrief_low.pdf>.

45. Hawkes C, Ruel M. Value chains for nutrition In: Reshaping agriculture for nutrition and health. An IFPRI 2020 book. Fan S, PandyaLorch R, eds. Washington, DC: IFPRI; 2012: 73-82.

46. Downs S, Fanzo J. Managing Value Chains for Improved Nutrition. In: Good Nutrition: Perspectives for the 21st Century. Eggersdorfer M, Kraemer K, Cordaro JB, et al., eds. New York: Karger; 2016: 45-59

47. Fanzo J, Downs S, Marshall QE, de Pee S Bloem MW. Value chain focus on food and nutrition security. In: Nutrition and Health in a Developing World. Nutrition and Health. de Pee S, Taren D, Bloem M, eds. New York: Humana Press, Cham; 2017.

48. Beesabathuni K, Lingala S, Kraemer K. Increasing egg availability through smallholder business models in East Africa and India. Matern Child Nutr 2018; 14 Suppl 3: e12667.

49. Alders RG, Dumas SE, Rukambile E, et al. Family poultry: Multiple roles, systems, challenges, and options for sustainable contributions to household nutrition security through a planetary health lens. Matern Child Nutr 2018; 14 Suppl 3: e12668.

50. Wong JT, de Bruyn J, Bagnol B, et al. Smallscale poultry and food security in resourcepoor settings: A review. Glob Food Sec 2017; 15: 43-52.

51. Völkel I, Schröer-Merker E, Czerny C-P. The carry-over of mycotoxins in products of animal origin with special regard to its implications for the European food safety legislation. Food Nutr Sci 2011; 2(8): 852-67.

52. Legesse Debela B, Demmler KM, Klasen S, Qaim M. Supermarket food purchases and child nutritional outcomes in Kenya, Global Food Discussion Papers 120. Göttingen: Universität Göttingen, Research Training Group (RTG) 1666 - GlobalFood, 2019. Available at <http://hdl.handle.net/10419/179500 > 
53. Demmler KM, Ecker O, Qaim M. Supermarket shopping and nutritional outcomes: A panel data analysis for urban Kenya. World Dev 2018; 102: 292-303

54. Demmler KM, Klasen S, Nzuma JM, Qaim M. Supermarket purchase contributes to nutritionrelated non-communicable diseases in urban Kenya. PLoS One 2017; 12(9): e0185148.

55. Rivera JA, de Cossio TG, Pedraza LS, Aburto TC, Sanchez TG, Martorell R. Childhood and adolescent overweight and obesity in Latin America: A systematic review. Lancet Diabetes Endocrino/ 2014; 2(4): 321-32.

56. Barquera S, White M. Treating obesity seriously in Mexico: Realizing, much too late, action must be immediate. Obesity (Silver Spring) 2018; 26(10): 1530-1.

57. Aburto TC, Pedraza LS, Sanchez-Pimienta TG Batis C, Rivera JA. Discretionary foods have a high contribution and fruit, vegetables, and legumes have a low contribution to the total energy intake of the Mexican population. $J$ Nutr 2016; 146(9): 1881s-7s.

58. Colchero MA, Rivera-Dommarco J, Popkin BM, Ng SW. In Mexico, evidence of sustained consumer response two years after implementing a sugar-sweetened beverage tax. Health Aff (Millwood) 2017; 36(3): 564-71.

59. Barquera S, Hernández-Barrera L, Rothenberg SJ, Cifuentes E. The obesogenic environment around elementary schools: Food and beverage marketing to children in two Mexican cities. BMC Public Health 2018; 18(1): 461.

60. Barquera S, Campos I, Rivera JA. Mexico attempts to tackle obesity: The process, results, push backs and future challenges Obes Rev 2013; 14 Suppl 2: 69-78.

61. Secretaría de Salud. Informe final de resultados. Encuesta Nacional de Salud y Nutrición de Medio Camino 2016 (ENSANUT MC 2016). Cuernavaca: Instituto Nacional de Salud Pública, 2016. Available at <https:// www.gob.mx/cms/uploads/attachment/ file/209093/ENSANUT.pdf>

62. Kaufer-Horwitz M, Tolentino-Mayo L, Jauregui A, et al. [A front-of-pack labelling system for food and beverages for Mexico: A strategy of healthy decision-making.]. Salud Publica Mex 2018; 60(4): 479-86.
63. Barrera LH, Rothenberg SJ, Barquera S, Cifuentes $E$. The toxic food environment around elementary schools and childhood obesity in Mexican cities. Am J Prev Med 2016; 51(2): 264-70.

64. Berhane G, Hoddinott J, Kumar N. The impact of Ethiopia's Productive Safety Net Programme on the nutritional status of children: 2008-2012. ESSP Working Paper 99. Washington, DC and Addis Ababa: International Food Policy Research Institute (IFPRI) and Ethiopian Development Research Institute (EDRI), 2017. Available at <http://www.ifpri.org/publication/ impact-ethiopias-productive-safetynet-programme-nutritional-statuschildren-20082012>

65. Masters WA, Rosettie KL, Kranz S, et al. Designing programs to improve diets for maternal and child health: Estimating costs and potential dietary impacts of nutritionsensitive programs in Ethiopia, Nigeria, and India. Health Policy Plan 2018; 33(4): 564-73.

66. Menon R. Sustaining Innovations Community Health Outpost (Posyandu) - Lessons Learnt. International Conference on Community Development 2018; 1(1): 384-91.

67. White S, Schmidt W, Sahanggamu D, Fatmaningrum D, van Liere M, Curtis V. Can gossip change nutrition behaviour? Results of a mass media and community-based intervention trial in East Java, Indonesia. Trop Med Int Health 2016; 21(3): 348-64.

68. London School of Hygiene and Tropical Medicine, Global Alliance for Improved Nutrition. Description of Emo-Demo activities: Gerakan Rumpi Sehat Campaign. London: LSHTM, GAIN, 2015. Available at <http:// blogs.Ishtm.ac.uk/envhealthgroup/ files/2015/04/Emo-Demo-Descriptions. pdf $>$.

69. Dart J, Davies R. A dialogical, story-based evaluation tool: The Most Significant Change Technique. Am J Eval 2003; 24(2): 137-55.

70. Davies R, Dart J. The 'Most Significant Change' (MSC) Technique - A guide to its use. Melbourne: Monitoring and Evaluation NEWS, 2005. Available at $<$ https://mande.co.uk/special-issues/ most-significant-change-msc/>
71. Pinstrup-Andersen P, Watson D. Food Policy for Developing Countries. Ithaca: Cornell University Press; 2011.

72. Tendall DM, Joerin J, Kopainsky B, et al. Food system resilience: Defining the concept. Glob Food Sec 2015; 6: 17-23.

73. Hawkes C, Watson F. Incentives and disincentives for reducing sugar in manufactured foods: An exploratory supply chain analysis. A set of insights for Member States in the context of the WHO European Food and Nutrition Action Plan 2015-2020. Copenhagen: World Health Organisation Regional Office for Europe, World Health Organisation, 2017. Available at <http://www. euro.who.int/en/health-topics/diseaseprevention/nutrition/publications/2017/ incentives-and-disincentives-for-reducingsugar-in-manufactured-foods-2017>

74. United Nations Children's Fund. Strategy for Improved Nutrition of Children and Women in Developing Countries. A UNICEF policy review. New York: UNICEF, 1990. Available at <https://www.unicef.org/nutrition/files/ Unicef_Nutrition_Strategy.pdf>

75. Hawkes C. Identifying innovative interventions to promote healthy eating using consumptionoriented food supply chain analysis. J Hunger Environ Nutr 2009; 4(3-4): 336-56.

76. Hawkes C, Smith TG, Jewell J, et al. Smart food policies for obesity prevention. Lancet 2015; 385(9985): 2410-21.

77. Global Panel on Agriculture and Food Systems for Nutrition (GLOPAN). Food systems and diets: Facing the challenges of the 21st century. London: GLOPAN, 2016. Available at <http://glopan.org/sites/default/files/ ForesightReport.pdf $>$

78. Pinstrup-Andersen P, Herforth A. Food security: Achieving the potential. Environment. 2008 2008/09/01:48-61.

79. Alliance for a Green Revolution in Africa (AGRA). Africa Agriculture Status Report: The business of smallholder agriculture in subSaharan Africa (Issue 5). Nairobi: AGRA, 2017 Available at <https://agra.org/wp-content/ uploads/2017/09/Final-AASR-2017-Aug-28 pdf $>$. 
80. Herrero M, Thornton PK, Power B, et al. Farming and the geography of nutrient production for human use: A transdisciplinary analysis. Lancet Planet Health 2017; 1(1): e33-e42.

81. Reardon T, Tschirley D, Minten B, et al. Chapter 4: Transformation of African agrifood systems in the new era of rapid urbanization and the emergence of a middle class. In: Beyond a Middle Income Africa: Transforming African Economies for Sustained Growth with Rising Employment and Incomes. ReSAKSS Annual Trends and Outlook Report 2014. Badiane O, Makombe T, eds. Washington, DC: IFPRI, 2015. Available at <http://www. ifpri.org/publication/transformationafrican-agrifood-systems-new-era-rapidurbanization-and-emergence-middle>.

82. Goger A, Hull A, Barrientos S, Gereffi G, Godfrey S. Capturing the Gains in Africa: Making the most of global value chain participation. Durham: Duke University Center on Globalization, Governance and Competitiveness, 2014. Available at $<$ http://www.capturingthegains.org/pdf/ Capturing-the-gains-in-Africa-2014.pdf>

83. East Africa Trade Hub. The fresh fruit and vegetable markets of East Africa: An assessment of regional value chain actors, activities and constraints in Kenya, Tanzania and Uganda. Washington, DC: USAID, 2013. Available at <https://www.eatradehub.org/ the_fresh_fruit_and_vegetable_markets_ of_east_africa>.

84. World Bank Group. Enterprise Surveys: Biggest obstacle. Washington, DC: World Bank; 2019

85. Global Alliance for Improved Nutrition. Marketplace for Nutritious Foods. 2016 https://www.gainmarketplace.com (accessed April 11 2019). 
@ United Nations Children's Fund (UNICEF) and Global Alliance for Improved Nutrition (GAIN)

Permission is required to reproduce any part of this publication.

Permissions will be fully granted to educational or non-profit organizations.

Please contact:

UNICEF

Nutrition Section, Programme Division

3 United Nations Plaza

New York, NY 10017, USA

For citation: UNICEF, GAIN. Food systems for children and adolescents. Working together to secure nutritious diets. New York: UNICEF; 2019

\section{unicef}

With the support of the Ministry of Foreign Affairs of the Kingdom of the Netherlands 